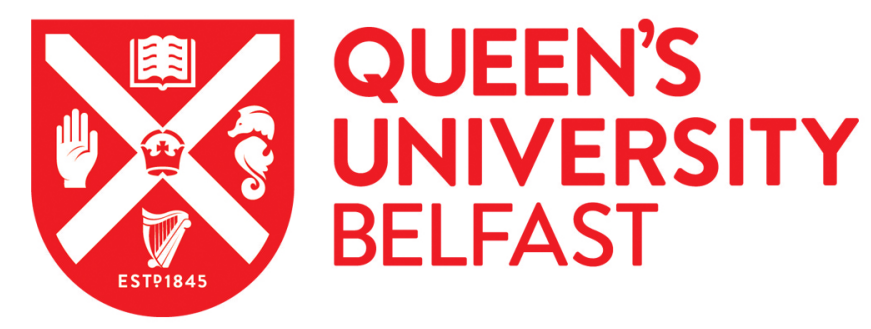

\title{
Does climate change information affect stated risks of pine beetle impacts on forests? An application of the exchangeability method
}

Cerroni, S., \& Shaw, W. D. (2012). Does climate change information affect stated risks of pine beetle impacts on forests? An application of the exchangeability method. Forest Policy and Economics, 72-84. https://doi.org/10.1016/j.forpol.2012.04.001

\section{Published in:}

Forest Policy and Economics

\section{Document Version:}

Peer reviewed version

Queen's University Belfast - Research Portal:

Link to publication record in Queen's University Belfast Research Portal

\section{Publisher rights}

Copyright @ 2012 Elsevier B.V.

This manuscript version is made available under the CC-BY-NC-ND 4.0 license (http://creativecommons.org/licenses/by-nc-nd/4.0/), which permits distribution and reproduction for non-commercial purposes, provided the author and source are cited.

\section{General rights}

Copyright for the publications made accessible via the Queen's University Belfast Research Portal is retained by the author(s) and / or other copyright owners and it is a condition of accessing these publications that users recognise and abide by the legal requirements associated with these rights.

Take down policy

The Research Portal is Queen's institutional repository that provides access to Queen's research output. Every effort has been made to ensure that content in the Research Portal does not infringe any person's rights, or applicable UK laws. If you discover content in the Research Portal that you believe breaches copyright or violates any law, please contact openaccess@qub.ac.uk. 


\title{
Does Climate Change Information Affect Stated Risks of Pine Beetle Impacts on Forests? An Application of the Exchangeability Method [Revised Draft for Forest Policy and Economics: February 14, 2012]
}

\author{
Simone Cerroni (corresponding author) \\ Department of Economics, University of Trento, Via Inama 5, 38122, Trento, Italy \\ Fondazione Eni Enrico Mattei, Corso Magenta 63, 20123, Milano, Italy \\ Email: simone.cerroni@unitn.it \\ Phone: +390252036963 \\ Fax: +390252036946 \\ W. Douglass Shaw \\ Department of Agricultural Economics and Hazard Reduction and Recovery Center, Texas A\&M \\ University, College Station, TX 77843-2124, USA \\ Email: wdshaw@tamu.edu
}

\begin{abstract}
Risks are an essential feature of future climate change impacts. We explore whether knowledge that climate change might be the source of increasing pine beetle impacts on public or private forests affects stated risk estimates of damage, elicited using the Exchangeability Method. We find that across subjects the difference between public and private forest status does not influence stated risks, but the group told that global warming is the cause of pine beetle damage have significantly higher risk perceptions than the group not given this information.
\end{abstract}

Key words: climate change; exchangeability; pine beetle; pine forest; stated risks. 


\section{Does Climate Change Information Affect Stated Risks of Pine Beetle Impacts on Forests? An Application of the Exchangeability Method}

\section{Introduction}

In a recent paper Bulte et al. (2005) consider the role that outrage and moral responsibility have in the determination of maximum willingness to pay (WTP) to reduce negative environmental outcomes, using a field experiment. They find that the WTP to protect seals relates to the nature or cause of the threat to the seals. Similarly, here we are interested in knowing whether the nature of the threat to forests matters, not in the determination of an individual's WTP, but in the formation of risk perceptions of forest damage. In particular, we want to understand whether explicitly framing climate change as the source of the pine beetle infestation affect laypersons' perceptions.

We use laboratory experiments to explore whether specifically stating the essential cause of an environmental outcome matters in eliciting subjective environmental risks. The cause of interest is global warming and the risky outcome we consider is future pine beetle destruction of private or public forests. Climate change may increase the destructive capability of the pine beetle, which attacks pine forests in several places in the United States, including the state of Texas. Given scientific controversy about risks related to climate change, public support for mitigation and adaptation policies on forestry sector can be strongly influenced by laypeople's assessments or perceptions about those risks (Leiserowitz 2005).

The International Panel on Climate Change (IPCC) uses the word "risk" to characterize a possible range of outcomes related to climate change, and these risks 
themselves may be uncertain. In particular, risk is a combination of probability of an event and the severity of the event, given it occurs. Knowing the probability is essential if an economist wishes to use the common economic framework to assess risky choices or options, which is the expected utility model (EU).

Even the most basic element of climate change, the average temperature that may occur at a particular date, is typically described using a range, rather than a point estimate, and competing models of global circulation assign different probabilities to these ranges, as well as other outcomes such as sea level rise. If the experts in the science community cannot pinpoint estimates of the probabilities that characterize the risks of climate change, then the public might be expected to form their own opinions about them. Perhaps this is why some individuals in the public seem certain that global warming is already happening, and others seem certain it is not and never will (e.g., Bostrom et al. 1994; Leiserowitz 2005; 2006; Weber 2006).

If subjective probabilities can be formulated, then the subjective expected utility framework (SEU) can be substituted for the EU framework. However, we note that the SEU framework most often assumes that individuals collapse their uncertainty into a degenerate expected value, ultimately thus being a risk framework and not one of uncertainty (Riddel 2011 makes this point). All of this makes it of great interest to ascertain subjective estimates of risk in the case of global warming impacts.

Our main application here relates to an approach to risk elicitation. Methods for uncovering subjective probability estimates vary from the most simple approach one could imagine (just ask) to more complicated approaches, such as the one we use here, called the Exchangeability Method (EM). While risk elicitation is common in decision 
analysis, particularly for studies of financial risk and uncertainty economics, it is much less used in the context of environmental and resource economics. Probability or risk elicitation here should not be confused with elicitation of risk preferences, wherein some method is used to determine an individual's level of aversion to risk, which is most often related to decisions involving tradeoffs and financial outcomes. Risk preference studies do not directly allow recovery of the individual's estimate of the probability of an outcome, though coefficients of risk aversion can be recovered from the data and used to estimate EU models that correspond to particular functional forms of risk aversion, such as the popular Constant Absolute Risk Aversion (CARA) form.

Much like elicitation of values, a risk elicitation mechanism guarantees reliable risk estimates if it provides subjects with some type of an incentive to state their real beliefs or preferences (e.g. see Vossler and Evans, 2009). Despite many kinds of incentives that may accomplish this, many economists take the view that only monetary incentives can succeed in ensuring incentive compatibility. This discussion has largely been in the domain of experimental economics, conducted in the laboratory. For example, the probability scoring method has been implemented as an incentive compatible approach to eliciting probabilities, when the gambles can be easily played out. Again, these are typically going to involve simple financial lotteries or gambles (see Savage 1971; Karni 2009). However, many economic studies, as well as laboratory studies in psychology involve hypothetical choices or scenarios, as ours does here (see Manski, 2004).

The problem in the context here is one that will nearly always be encountered when the outcomes are large scale environmental outcomes, or health outcomes, for the 
simple reason that these cannot be played out in the laboratory. In part to address this issue, Fiore et al. (2009) set up a virtual reality experiment involving forest fires, which are a clear-cut example of something that cannot be played out in the laboratory. The outcomes are instead played out in the virtual world, which is supposed to more closely mimic the real world that simple picture or verbal text. Subjects see the fire using virtual reality devices, but of course cannot feel the heat, nor do they actually own property that may be destroyed by the forest fire. Fiore et al. (2009) do not attempt to elicit individual's perceptions of forest fire risks, assuming instead that the probabilities that reveal risk attitudes relate to money gambles. We are not willing to concede that risk attitudes for money will carry over to risk attitudes for other outcomes, at least in every situation.

A lot of research, much in the psychology literature, has demonstrated that risk or probabilities are very difficult for the layperson to understand and recommend different approaches for communicating risks to people and then eliciting their best estimate (e.g., see Corso et al. 2001; Gigerenzer and Hoffrage 1995; Hammit and Graham 1999). Just asking a person to state what they believe a probability is can be fraught with difficulty. Even when the best available estimates from scientists are presented as information, individuals who are asked seem to ignore this information, or form opinions that might be orders of magnitude away from the science (e.g., see Riddel and Shaw 2006). Hence, in this paper we implement a rediscovered, but quite old method of eliciting probabilities, the EM. The EM relies on the definition of exchangeable events as formulated by de Finetti in 1937. To our knowledge, though recently rediscovered by Baillon (2008) and Abdellaoui et al. (2011), this approach has not yet been used for eliciting environmental risk perceptions in empirical studies. 
Using the EM, our subjects are not directly asked to state forest damage probability estimates. Instead, as will be explained below, our subjects are asked a series of choice questions that essentially reveal points on each subject's cumulative density function $(\mathrm{CDF})$, where the probability relates to whether the forests will be damaged by the pine beetle. Using the exchangeability method we hope to avoid the usual problem of subjects' understanding of probabilities, especially small ones (see Manski 2004). As researchers we indirectly infer the probability subjects attach to those outcomes, which is possible because of the solid statistical theoretical foundation for the EM (Chew and Sagi, 2006). Using this EM framework, our main hypothesis is that stated or elicited risk estimates may be influenced by the underlying cause of pest damage.

The remainder of the paper is as follows. After very briefly reviewing the literature on elicitation of environmental risk, we explain the exchangeability method of risk elicitation and describe the way that our experimental study was implemented. Results for pine beetle risk estimates are presented and discussed in the final sections. Our tests of the consistency of responses provide some support for the notion that subjects answer questions reliably.

\section{Perceptions and Policy Implications}

The IPCC provides a good deal of scientific evidence that climate change will change forest ecosystems all around the world. Note that in colder regions, forest ecosystems may gain from climate change because both temperature and precipitation will slightly increase, but in warmer regions, forests may be negatively impacted by this same trend because of desertification: conditions will become too hot and dry. In 
currently dry or arid regions, the risk of further droughts may reduce forest net ecosystem productivity (NEP) and increase the risks of wildfires and insect pests (IPCC 2007).

Specific impacts differ in different regions of the planet, but this trend is likely for the state of Texas, where scientists predicts that higher temperatures and lower precipitation will increase the chance of Southern Pine Beetle outbreaks or attacks. This insect already threatens pine forests in many other states, for example Alabama and Georgia. In Texas, most of the pine forests are in the east part of the state, where they cover an area of around 12 million acres. From 1970 to 1996, the annual average volume of timber killed in Texas by southern pine beetle was almost 184,000 cubic meters for a value of about \$ 120 million (Gan 2004).

Policies to protect forests from further pine beetle destruction are possible, but need public support, and in Texas, as in most states within the United States, that translates to support of the state government. Given the high degree of uncertainty related to science-based estimates of climate-change risks, decision makers, including government officials, often make decisions according to their subjective estimates of those risks rather than on scientific predictions (Norris and Kramer, 1990). As an example, Pingali and Carson (1985) have shown that fruit farmers' demand for different pest management strategies strongly depend on their perceptions of the damages to the orchards. More recently, Pregerning (2002) found that forest owners' choices to engage in restoration measures also rely on subjective perceptions of the urgency of the problem.

Perceptions relate to willingness to support public investments in environmental protection, and if either the public, or the government, or both fail to believe something is a serious problem, then no resources will be forthcoming for that protection. For example, 
Viscusi and Zeckhauser (2006) showed that Americans who have higher perceptions of future temperature increases are willing to pay more for policies which address global warming. The perception or believe problem may also be an issue in the case of Texas forest owners who need to plan and implement forest management controls to avert the risk of pine beetle infestation in the future, or state government officials involved in funding such programs.

By investigating laypeople's perceptions of the pine beetle's infestation rate, we aim to provide policy makers with useful information about public knowledge, concern and sensitivity to the issue. Based on scientific information provided by expert assessments and laypeople's perceptions, policy makers will be able to plan forest management strategies that will be effective in controlling the pest and agreeable to citizens. The knowledge of factors determining the formation of laypeople's perceptions may help policy maker to better communicate environmental risks and design efficient campaign to promote the acceptability of risk-mitigation strategies.

\section{Literature review}

The literature on subjective probabilities and risk elicitation spans the fields of economics, psychology, and decision theory, and is much too vast to adequately cover here. The elicitation of risk, and more specifically, probabilities, is a relatively new research area in the context of environmental and resource economics, even though it has long been done in other contexts such as financial and health risks. To keep the current paper of manageable length and still adequately explain the EM, we refer the reader to more lengthy reviews of this literature (e.g., Viscusi, 1990; Dominitz and Manski, 1997; Manski, 2004; Shaw and Woodward, 2008; Andersen et al. 2010). We note that many 
empirical researchers have elicited qualitative measures of environmental risks, either indirectly or directly (Spetzler and Von Holstein, 1975). For example, Siegrist and Gutsher (2006) asked both experts and laypeople to indicate the qualitative measures of flood risk for different regions of Switzerland. In a similar study in the Netherlands, Botzen et al. (2009) elicited not only qualitative, but also quantitative flood risk measures, directly asking people to express a point estimate of the probability of flood occurrence at their own home. Many studies applying direct risk elicitation approaches have used visual aids, such as risk ladders or risk grids to assist subjects in forming their estimates of probability. The beneficial effect of visual aids in risk communication has been empirically demonstrated in several stated preference studies investigating the WTP for health risk reductions. When visual aids are used the estimates are consistent with theoretical expectations (Hammit and Graham, 1999; Corso et al., 2001; Visschers et al., 2009).

Despite these direct risk elicitation methods being very popular, scholars are still not sure of the reliability or accuracy of risk estimates elicited via this family of techniques. In contrast to direct techniques, one can indirectly infer subjective probabilities from individual choices over lotteries and for gambles or bets. These "indirect methods" have been widely used in experimental and behavioral economics, especially in the context of financial risks (e.g., Andersen et al., 2010). Choosing between two or more financial lotteries may be difficult for respondents because they have to make trade-offs between pairs of risky outcomes, considering both the magnitude of the environmental outcome and the probability of occurrence. Again, this may affect the reliability of subjective risk measures elicited using indirect methods. 
Given concerns about the usual methods, and out of curiosity to see if it could be applied, we decided to elicit subjective risk estimates by using the recently resurfaced exchangeability method (Baillon, 2008; Abdellaoui et al., 2011). We chose the EM among many other indirect methodologies or games where probabilities can be elicited because of several attractive features. First, it is a relatively straightforward game to play. Second, it potentially allows elicitation of as many point estimates of each respondent's cumulative distribution function as the researcher feels she needs, subject to the respondent becoming exhausted.

Finally, whereas many risk elicitation techniques are biased by source dependence, the EM is not. Some experimental studies have shown that individual choices depend on the source of uncertainty respondent have been told to consider (Kilka and Weber, 2001). When individuals have to simultaneously process more than one source of uncertainty ${ }^{1}$ their risk estimates might be biased. This is likely to occur in lottery games where subjects have to deal with uncertainties related to both outcomes and probabilities. In contrast, when using the EM approach the subjects have only to deal with the outcomes. Naturally, all elicitation techniques have limitations, and the EM consists of chaining questions which may undermine the incentive compatibility of the game as well as the reliability of stated risk estimates (Wakker and Defenne, 1996; Baillon, 2008). Thus, below we test the consistency of subjects' answers as a check on the reliability of the elicitation technique.

\footnotetext{
${ }^{1}$ Baillon (2008) defines a source of uncertainty as "... a set of events that are generated by a common mechanism of uncertainty."
} 


\section{Possible Influences on Forest Damage Estimates}

Rocky Mountain (Colorado) and Southern region U.S. pine forests have been historically threatened by the pine beetle (see Holmes, 1991). The problem has been growing rapidly in many regions of the U.S., leading to vast amounts of acreage of dead pine trees. The dead trees are unsightly (brown), and also pose an increased forest fire risk. In Texas, scientists predict that future increases in temperature and decreases in precipitation will facilitate the spread of threats by the Southern Pine Beetle (Gan, 2004). We focus on the potential increases in risk, expressed as the percentage of pine trees damaged or killed by the pine beetle between the period between 2010 and 2050 .

We hypothesize that, when provided with information on climate change being the source of pine beetle infestation, respondents will change their subjective perceptions of pest risk based on their beliefs about climate change impacts. Some individuals may cling to their prior beliefs, and may predict future events in a fashion consistent with those (e.g., the "home team betting" phenomenon, Viscusi and Zeckhauser 2006). Thus, we also expected that some of our subjects would not believe in climate change as a factual phenomenon and that, when provided with information on climate change, skeptical subjects would not change their priors on the pest risk, or even reduce them. For other subjects who believe in climate change, the provision of the same information might raise a sense of alarm, leading them to increase their estimate of the percentage of damage to the forest associated with any given probability. We define these potential influences of people's climate change beliefs on risk perceptions as a "climate change" effect. 
We also investigate whether respondents' risk perceptions differ for public and private forests: we have no priors on which direction of influence forest status might have on risks, if any. In the survey, respondents are informed that the infestation rate is equal for both forest types in 2009 and that no pine beetle control will be implemented (this is quite reasonable in the forest sector). The only difference between public and private forests is the property rights people have to access lands and manage productive activities (i.e., harvest timber).

Subjects who regularly engage in forest-based recreation may wish that forests will be protected in the future, and forecast this in their future risk estimate. Alternatively, strong concerns for the health status of forests they visit may result in higher estimates of infestation risk. Moreover, these individuals may not care about forests that are privately managed, and this lack of concern might be reflected in lower risk estimates. Risk perceptions of subjects who have ties to the forest industry may also be different from subjects with no such ties.

All these phenomena are related to the fact that some subjects have a utility function that relates to forest protection. However, confounding the analysis is the fact that some subjects' utilities are more directly related than others because they may have stakes in the outcomes. When utilities and perceived risks cannot be disentangled, the assumption of state-independent preferences may be violated, and hence the definition of unique subjective probabilities is difficult, or even impossible to formulate (Karni, 1993) 2 . If preferences and subjective probability estimates are related, then choice-based

\footnotetext{
${ }^{2}$ Dreze (1987) and Karni (2009) have developed alternative methods to elicit subjective probabilities when utilities are state dependent. Their approaches rely on the presence of moral hazard, in the sense that subjects have the chance to take actions that modify the likelihood of the risky outcome. However, our investigation excludes moral hazards as subjects have been told to assume that no destroyed trees will be replaced (replanted or restored) in the future scenarios.
} 
elicitation techniques may provide biased results of the subjective probability estimates. Here, we cannot formally demonstrate that risk estimates for those with stakes in the outcomes (with ties to the forestry industry, for example) are biased as compared to the others, but we can at least compare the magnitude of risk estimates for the two groups. We investigate whether subjects with stakes (possibly with state-dependent utilities) will under- or overestimate perceived risks as compared to the subjects who have no stakes and whether such discrepancy significantly affect our results. We provide these results in section 8.2.

\section{Exchangeability method}

The EM uses a series of binary questions to reveal an individual's underlying cumulative distribution function (CDF) over an event $x$ that is drawn from an event space, $S_{A}$. The first step of the EM establishes the lower and upper bounds of the event space, say $S_{0}$ and $S_{100}$. Each subject is asked the bounds on outcomes outside of which they are essentially certain the outcome cannot happen at all - i.e., the bounds that contain a nonzero probability of an outcome. The bounds of course may differ for each individual, and with complete ignorance of the problem, a rather wide range of bounds might be involved for most subjects (at the extreme, something cannot happen, or it definitely must, or will happen). Note that if priors can be elicited that are consistent with the estimates that arise during the implementation of the EM game, then one might motivate what happens here using Viscusi’s (1989) Prospective Reference Theory, a simple Bayesian updating model. ${ }^{3}$

The second step involves asking a series of questions that establish the value of $S_{50} \in S_{A}$ that corresponds with the $50^{\text {th }}$ percentile of the subjective CDF, the median

\footnotetext{
${ }^{3}$ We thank an anonymous reviewer for pointing this out.
} 
estimate. This series of questions asks the subject to choose between binary prospects. In the first binary question, $S_{A}$ is divided at a point $k_{l}$ into two prospects, say $A_{1}=\left\{S_{0} \leq x \leq k_{l}\right\}$ and $B_{1}=\left\{k_{1}<x \leq S_{100}\right\}$, where $k_{l}=\left\{S_{0}+\left[\left(S_{100}-S_{0}\right) / 2\right]\right\}$. If $A_{1}$ was chosen by the individual, the implication is that the individual believes $P\left(A_{1}\right) \geq P\left(B_{1}\right)$, so that $k_{l} \geq S_{50}$. A follow-up binary question is then asked of this same individual, using a new value $k_{2}$ and two new prospects $A_{2}$ and $B_{2}$. If $A_{1}$ was chosen in the first question, then $k_{2}<k_{1}$. However, if $B_{1}$ was chosen in the first question, then $k_{2}>k_{1}$. This process is repeated until the individual reaches a value $k_{n}$ such that she is indifferent between $A_{n}$ and $B_{n}$. When this point is reached, it follows that $k_{n}=S_{50}$. This series of questions have been used to arrive at a point estimate that corresponds to the median point for the CDF.

A similar process can be followed to determine other points for the individual's subjective CDF; in theory as many as the researcher wants, but of course limited by patience and cognition of the subject. To determine the value of $S_{25} \in S_{A}$ that corresponds with the $25^{\text {th }}$ percentile, a gamble is proposed that is contingent on a value of $x$ that is lower than $S_{50}$, obtained in the previous step. Once again, a sequence of values, $k_{1}, k_{2}, \ldots$, $k_{\mathrm{n}}$ is used, but in this case the initial upper bound is $S_{50}$. In the first new binary question, subjects choose between the following binary prospects, $A_{1}=\left\{S_{0} \leq x \leq k_{1}\right\}$ and $B_{1}=\left\{k_{1}<x \leq\right.$ $S_{50}$. As above, without changing the upper bound, this process is repeated until the individual is indifferent between $A_{n}$ and $B_{n}$, so that $k_{n}=S_{25}$ (see Figure 1). At the end of this procedure, we know that there is 25 percent chance that the percentage of damaged forest will be less than or equal to $S_{25} \in S_{A}$.

As noted above, even when respondents are provided with monetary incentives based on their choices during the game, the EM is not necessarily incentive compatible. 
The sequence or chain of questions, which, upon completion reveal the point on the CDF, gives rise to doubt (see Baillon 2008). In their similar EM investigation, Abdellaoui et al. (2011) find evidence that real payments implemented using the same incentive scheme as Baillon (2008) has are less noisy than scenarios run without actual payments made. However, scrutiny of the CDFs for the real versus hypothetical treatments by Abdellaoui et al. (2011) reveals little difference between the scenarios with payment and without (see their Figures 6 and 7). In any case, there is no dominant strategy that respondents can follow over the series of questions used in the EM, and telling the truth about their beliefs may indeed be the simplest strategy for them (Baillon 2008).

For our application here (to see if climate change influences risk estimates), consistency in the obtained data is all that we can explore. Thus, we focus on testing the consistency of subjects' responses with some qualitative predictions that we formulate.

\section{Implementation}

In our implementation of the EM, done in the laboratory using a computerized version of the survey, subjects are asked to assess the percentage of the forest that will be damaged and destroyed by the pine beetle during the period between 2010 and 2050. A focus group ran prior to implementation suggested that subjects would respond best to losses couched as the percentages of a forest that are harmed, as opposed to specific numbers of trees or loss in volume, such as board feet or acreage. Some previous psychological studies on risk communication have shown that people better understand probability when they are expressed as frequencies (e.g., Gigerenzer and Hoffrage, 1995).

Our programming software did not allow each individual's initial range of the upper and lower bound to be input, and it was expected that few subjects would have any 
prior knowledge of pine beetle damage, so we simply begin with the largest possible range for every subject: from $S_{0}=0 \%$ (no damage will happen) to $S_{100}=100 \%$ (the entire forest will be destroyed). Using these fixed lower and upper bounds rather than subjects' minimum and maximum expectations may induce the elicitation of biased risk measures. To examine this issue, we simulate subjects' behaviors as if they have prior lower and upper bounds which are different from those we provided. Then, we compare subject's real and simulated choice behaviors in order to check the consistency of our risk estimates (see Section 8.1.3, below).

Each binary question consists of two complementary percentage ranges of the forest that could be destroyed by the pine beetle. The set of first binary questions to determine the median probability (i.e., the value of $S_{50} \in S_{A}$ that corresponds with the $50^{\text {th }}$ percentile) begins with the choice between prospect $A_{1}=\left\{0 \% \leq x \leq k_{l}\right\}$ and $B_{1}=\left\{k_{l}<x \leq\right.$ $100 \%\}$, where $k_{l}=\{0 \%+[(100 \%-0 \%) / 2]\}=50 \%$ (see Figure 2). Following the first choice, the exercise is repeated using a bisection of the chosen prospect, this time beginning with the new implied midpoint for the range from the first prospect. For example, if the subject chooses the lower range $A_{1}$, then the second binary question splits the chosen prospect into $A_{1}=\{0 \% \leq x \leq 25 \%\}$ and $B_{1}=\{25 \%<x \leq 50 \%\}$. Once that second choice is made, the event space for the chosen prospect is split again. This bisecting process goes on until each prospect of the binary question does not cover a space smaller than 5 percent. At this point we pause and identify the estimate of the $50^{\text {th }}$ percentile $S_{50}$. We interpret this estimate to indicate the percentage of forest where the subject believes there is a 50 percent chance that the proportion of forest that might be destroyed is equal to or less than this, over the period. 
A new sequence of binary questions begins, enabling identification of $S_{25} \in S_{A}$ which corresponds with the $25^{\text {th }}$ percentile. This new series of questions is contingent on the value $S_{50}$ obtained from the first sequence, so that the first binary question is between the prospect $A_{1}=\left\{0 \% \leq x \leq k_{1}\right\}$ and $B_{1}=\left\{k_{1}<x \leq S_{50}\right\}$, where $k_{1}=\left\{0 \%+\left[\left(S_{50}-0 \%\right) / 2\right]\right\}$. This procedure goes on until the range is small enough to identify the estimate of the $25^{\text {th }}$ percentile $S_{25}$. Similar to above, our interpretation of the final value is that it reveals the percentage of forest where the subject believes there is 25 percent chance that the proportion of forest that might be destroyed is equal to or less than this.

After that is completed, a new sequence of questions is implemented following the same logic to estimate $S_{75} \in S_{A}$ corresponding to the $75^{\text {th }}$ percentile. In this case, there is 75 percent chance that a percentage of forests less than or equal to the estimated value of $S_{75}$ will be destroyed.

To avoid fatigue of the subjects, our study confines estimates to these three probability points; thus, in this manner, the indifference points for the events corresponding to the cumulative probabilities are found, allowing us to map out a portion of the subjective CDF for each subject.

\section{Sample and Survey Design}

Our subject pool consists of 134 Texas A\&M undergraduate students from a range of subject disciplines. They were randomly selected by using the informatics platform of the Texas A\&M Economics Research Laboratory where undergraduate students can register themselves in order to participate to economics experiment. The experiment was carried out at the Texas A\&M Economics Research Laboratory in March 2010. Each subject was paid a flat $\$ 10$ participation fee and provided with the basic rules 
of the economic laboratory. Note that in what follows, we use wording commonly used in experimental economics, even though our choice tasks are hypothetical.

The experiment consists of five experimental sessions and five groups of subjects, one group for each session (Table 1). Hence, one group of subjects only participates in one session. Each session corresponds to a specific experimental treatment, in each treatment subjects are presented with different information. Four of these group treatments can be thought of as between-subjects experimental treatment investigations. In the first session, all of the subjects are told that the impacted forest is a public access forest ("public forest-no climate change" treatment), and in the second session all are told that the impacted forest is private ("private forest-no climate change" treatment). In each of these first two treatments, subjects have been told that the pine beetle infestation likely occurs, and depends on an increase in temperature and a decrease in precipitation, but the terms "climate change" or "global warming" were not mentioned. In the third session, we provide the same information as in the first treatment group, but we also specifically describe climate change as the cause of possible increases in pine beetle infestation on a public access forest ("public forest-climate change" treatment). The fourth session is similar, combing session two's private forest with the climate change cause ("private forest-climate change" treatment). Finally, the fifth session is a within-subjects investigation of the public versus private forest effect in which climate change is not mentioned ("public \& private forest-no climate change"). In this last session the sample is also split in two sub-samples: one sub-sample receives a scenario where they are first asked to assume the forest is public access ("public-private" treatment), then the exercise is repeated for a private access forest ("private-public" treatment); the other sub-sample 
faces a scenario where the order of the exercises is reversed, to allow a test for order effects. This last treatment was undertaken to allow exploration of the private versus public effect for each individual subject.

After the experimental instruction have been provided, all subjects in all sessions are next asked whether they have any familiarity with the pine beetle issue and to provide a simple guess of the chance that a pine beetle infestation that destroys 10 percent of the forest will happen (i.e., we asked for a guess at the point estimate or, in case respondents were not able to do that, a stated range estimate). Then we provide them with specific information about the acreage of forests that has been damaged by the pine beetle in the period between 1960 and 2009. Identical pictures of healthy and damaged forests are shown to all subjects, no matter which treatment group they belong to. They have also been told that this insect dies when very cold temperatures are reached, and that it thrives when warm and dry climatic conditions happen. Further information has been given to subjects depending to the experimental treatment they belong to. At this point, they have all information to start playing the Exchangeability game (Appendix A). All subjects are also asked to play the game assuming that no destroyed trees will be replaced (replanted or restored) in the future scenarios, so that the baseline future conditions are the same for all subjects.

After the Exchangeability game is completed, all subjects are also asked whether they would agree with statements that climate change is going to raise temperatures (Appendix A). In addition, they are asked a series of demographic questions, including their household income, gender, whether they engage in recreation in any public Texas forests, and years of residence in Texas. Ideally, incentive compatibility is desirable, and 
if we could, we would play out a draw to yield the probability that forests are damaged, and then go ahead and damage the forest, letting the subjects witness this actual process. This is of course impossible, unless one resorts to some sort of computer simulation or stylized representation of the forest being damaged (for example, killing only one part of one tree which symbolizes the killing of many trees). Despite this, we know of no other application of the EM to an environmental or resource problem and do not know of any attempt to elicit pine beetle damage risks, as we do here.

Finally, simply to increase the subjects' potential monetary reward for participating in our experiment, keep them in the room, and keep them focused on the questions, subjects were told at the beginning that after all tasks were completed, two randomly drawn subjects from each treatment group engaged in a coin toss game ${ }^{4}$. Four questions for each selected subject were randomly drawn and the winning outcome for the drawn questions was determined by a coin toss. The drawn subjects was paid if their choices to the drawn questions corresponded to the winning outcomes, otherwise they earned nothing.

Given that the coin toss (with a $50 \%$ probability of a win) had no connection to the damage probability estimates, as would be true in a probability scoring approach, this procedure could have potentially biased subjects' behavior, possibly inducing them to just randomly choose between outcomes. ${ }^{5}$ However, as the context of the draw for a win was focused on being randomly chosen among all the subjects, as well as having a particular question chosen, we do not think the subjects would confuse the EM game choices with the choice for a coin toss. Still to reduce doubt about this issue, we test for

\footnotetext{
${ }^{4}$ The maximum possible reward for participant was $\$ 200$, excluding the participation fee

${ }^{5}$ A reviewer raised this possibility.
} 
the consistency of subjects' choices during the game and we find that their behaviors are consistent with several qualitative predictions we formulate. Detailed results are presented below in Section 8.1.3.

\section{Specific Hypotheses}

The key response variables under study for the five treatments are all elicited percentages of damaged forest by the pine beetle during the period between 2010 and 2050 , corresponding to three key points of the subject's $\operatorname{CDF}\left(\mathrm{S}_{25}, \mathrm{~S}_{50}\right.$, and $\left.\mathrm{S}_{75}\right)$.

The hypotheses that we test are the following:

1. The subjective infestation risk of the southern pine beetle on public access forests is the same as the subjective infestation risk distribution for privately owned forests. For example, for $\mathrm{S}_{25}$, the null is $\mathrm{H}_{\mathrm{o}}$ to be compared to the alternative, $\mathrm{H}_{1}$ :

\footnotetext{
$\mathrm{H}_{0}$ : distribution $\left(\mathrm{S}_{25}\right)_{\text {public-no climate change }}=\operatorname{distribution}\left(\mathrm{S}_{25}\right)_{\text {private-no climate change }}$ $\mathrm{H}_{1}$ : distribution $\left(\mathrm{S}_{25}\right)_{\text {public-no climate change }} \neq$ distribution $\left(\mathrm{S}_{25}\right)_{\text {private-no climate change }}$
}

2. The subjective infestation risk on a public access forests when climate change is mentioned is the same when climate change is not mentioned. For example, for $S_{25}$ :

$$
\begin{aligned}
& \mathrm{H}_{0} \text { : distribution }\left(\mathrm{S}_{25}\right)_{\text {public-no climate change }}=\operatorname{distribution}\left(\mathrm{S}_{25}\right)_{\text {public-climate change }} \\
& \mathrm{H}_{1} \text { : distribution }\left(\mathrm{S}_{25}\right)_{\text {public-no climate change }} \neq \operatorname{distribution}\left(\mathrm{S}_{25}\right)_{\text {public-climate change }}
\end{aligned}
$$

We use two different strategies in order to tests these hypotheses. First, we essentially separately compare the distributions of each elicited percentages of damaged 
and killed trees between treatment groups by using standard nonparametric tests. Second, we provide a simple behavioral/regression model explaining how environmental attitudes, socio-economic factors, and treatment effects influence subjects' pest risk perceptions. The power of the regression model stems from the larger sample, and allows a check on the robustness of the non-parametric tests. In addition, it allows us to consider the role that demographic and other variables for which survey data is available might play in explaining the variation of revealed risks.

\section{Results}

\subsection{Nonparametric tests}

The potential effects of ownership (forest access) and climate change can be initially assessed by analyzing the difference in the variables under study $\left(S_{25}, S_{50}\right.$, and $\mathrm{S}_{75}$ ). To preview, we find that means and standard deviations do not differ between "public" and "private" treatments, but they do between "climate change" and "not climate change" information treatments (Table 2, Figure 3 and Figure 4).

In all between-subjects analyses, Kolmogorov-Smirnov tests (KS) were also conducted in case the reliability of the Mann-Whitney $U$ test (MW) was compromised by the violation of the assumption of similar shapes between the two population distributions from which the data were obtained. In all within-subjects analyses, we tested our hypotheses first through the Wilcoxon matched-pairs signed-ranks test (WMP) and then through the Sign test of matched pairs (SMP), in case the reliability of the first test was compromised by the violation of the assumption of symmetric distributions of the differences between variables' values for each subject. 


\subsubsection{Ownership/Access effect}

The effect of forest access or ownership is investigated through between-subjects and also within-subjects investigations (the fifth treatment). In the between-subjects investigations, the comparison of the subjective risks between "public forest" and "private forest" treatments is performed twice, once when climate change is not mentioned and again when it is mentioned. In the first case, we have two independent samples, "public forest-no climate change information" (38 subjects) and "private forestno climate change information" (43 subjects). Based on the KS test, we fail to reject the null hypothesis of identical distributions of the variables under study $\left(S_{25}, S_{50}\right.$, and $\left.S_{75}\right)$ between the two independent groups ("public forest-no climate change information" and "private forest-no climate change information") (see Table 3). In the two treatments where climate change is mentioned, assuming we still have two independent samples, there is a "public forest-climate change" sample (21 subjects) and a "private forestclimate change" sample (32 subjects). Here the KS test again lead us to fail to reject the null hypothesis of identical distributions of the variables under study $\left(\mathrm{S}_{25}, \mathrm{~S}_{50}\right.$, and $\left.\mathrm{S}_{75}\right)$ for the two independent samples. (Table 4). Results of the between-subjects investigations indicate that subjective risk perception is not influenced by the nature access to forests.

The within-subject investigation allows comparison of elicited risk for the same person. This analysis is performed without mentioning climate change. The fifth treatment group contains 30 subjects. As we expected, the WMP test rejects the null hypothesis of identical median values of the variables under study $\left(\mathrm{S}_{25}, \mathrm{~S}_{50}\right.$, and $\left.\mathrm{S}_{75}\right)$ : there are differences in risks elicited for the same person, depending upon access or 
ownership (Table 5). However, the SMP test does not lead to rejection of the null hypothesis of equal median values for $\mathrm{S}_{25}$ and $\mathrm{S}_{50}$, but does lead us to reject the null hypothesis of equal median values for private and public forests for $\mathrm{S}_{75}$ (Table 5), suggesting that subjective damage estimates for public forests are greater than for private forests $^{6}$.

Based on the within-subjects analysis, we conclude that subjective estimates of the percentages of damaged forest by the pine beetle during the period is higher for public forests than for private forests. The discrepancy in results between these two analyses (between versus within-subjects) is discussed below, in Section 9.

\subsubsection{Climate Change}

The role of climate change in affecting individual perceptions of the risk is analyzed using the between-subjects investigations. Recall that the group which receives climate change information also is differentiated into two groups, one presented with a public, and the other with a private forest. For comparison of the risk variables from "public-no climate change" (38 subjects) and "public-climate change" (21 subjects) groups, the KS test leads us to fail to reject the null hypothesis of identical distributions of the variable under study $\left(\mathrm{S}_{25}, \mathrm{~S}_{50}\right.$, and $\left.\mathrm{S}_{75}\right)$ for the two independent samples ("public-no climate change" and "public-climate change") (Table 6).

Last, we compare the distributions between "private-no climate change" (43 subjects) and "private-climate change" (32 subjects) samples. In this case, the KS test fails to reject the null hypothesis for $S_{50}$, but it rejects the null hypothesis for $S_{25}$ and $S_{75}$ (at 5\% and 10\% significance levels respectively). In both cases, we detect statistically

\footnotetext{
${ }^{6}$ Order effects may have mattered, so we tested for the effect of presenting subjects first with the public forest, then the private forest, and vice versa. The MW test demonstrates the absence of an order effects
} 
significant differences in the distributions of variables $\mathrm{S}_{25}$ and $\mathrm{S}_{75}$ when subjects are informed about climate change being the underlying cause of the pine beetle infestation, as compared to the treatment where the subjects are not told this (Table 7).

The above results about potential differences in perceptions of pest risk due to the source of the environmental risk are interesting, but further analyses are possible because previous results suggest that risk perceptions are not influenced by property rights on forests. We create two combined samples by pooling all observations of "private-no climate change" and "public-no climate change" into a "no climate change" sample and by pooling all observations of "private-climate change" and "public-climate change" into a "climate change" sample. The KS test rejects the null hypothesis of equal population distributions between the two samples ("climate change" and "no climate change") in all cases $\left(S_{25}, S_{50}\right.$, and $\left.S_{75}\right)$. Again, we found that distributions of the "climate change" sample differ from that of "no climate change" sample (Table 8).

We conclude that the distributions of the combined sample with no climate change information significantly differ from the distributions of the sample with climate change information. Climate change information appears to matter, increasing the subjective pest risk perceived by our subjects who are exposed to it.

\subsubsection{Consistency of subjects' choice behavior}

Next, following Baillon (2008), we check whether respondents' behaviors are consistent with some qualitative predictions. To begin, we choose for each respondent a value $s$ ' between her/his estimates of $S_{50}$ and $S_{75}$. Then, following the usual bisectioning process, we find an $s^{\prime \prime}$ such that $\left\{S_{25}<x \leq s^{\prime \prime}\right\}$ and $\left\{s^{\prime}<x \leq s^{\prime}\right\}$ are exchangeable 
partitions ${ }^{7}$. This implies that the value $s^{\prime \prime}$ should be between $S_{25}$ and $S_{50}$ and should be closer to $S_{50}$ than to $S_{25}\left(S_{25}<s^{\prime \prime}<S_{50}\right.$ and $\left.\left|S_{50}-s^{\prime \prime}\right|<\left|S_{25}-s^{\prime \prime}\right|\right)$ (Test 1$)$.

Consistency of respondents' choices are also tested using another approach from Abdellaoui et al. (2011) (Test 2). For this one we calculate a hypothetical value of $S_{50}$ for each respondent, $S_{50}{ }^{\prime}$, such that $\left\{S_{25}<x \leq S_{50}{ }^{\prime}\right\}$ and $\left\{S_{50}{ }^{\prime}<x \leq S_{75}\right\}$ are exchangeable partitions. Then we check if respondents' estimates of $S_{50}$ are consistent with hypothetical values of $S_{50}{ }^{\prime}\left(S_{50}=S_{50}{ }^{\prime}\right)$.

These hypotheses are tested using a parametric paired t test because the size of the whole sample is large enough for this scope. We found that all predictions are satisfied at the $10 \%$ significant level showing the consistency of respondents' choice behavior (Table 9). Consistency tests provide assurance that the paying subjects following a coin toss did not affect their choice behavior and that our scenarios are meaningful as compared to the more concrete contexts used by Baillon (2008) and Abdellauoi et al. (2011).

Furthermore, we test whether risk estimates obtained by providing all subjects with the same lower $\left(S_{0}=0 \%\right)$ and upper bounds $\left(S_{100}=100 \%\right)$ will affect subjects' choice behaviors. Subjects may have their own priors and therefore, our failure to allow for these may induce the elicitation of biased risk measures. ${ }^{8}$ It is likely that subjects start playing the game, first having in mind rough estimates of the percentage of damaged forest in the period 2011-2050. Hence, we assume that hypothetical subjects $i=\{1, \ldots, 13\}$ play the exchangeability game having the following priors $P S_{50}=\{20,25,30,35,40,45$, $50,55,60,65,70,75,80\}$. In particular, let subject 1 have outcome $P S_{50}=20$, subject 2 has outcome $S_{50}=20$, and so on, until subject 13 , has $S_{50}=80$. Using these hypothetical

\footnotetext{
${ }^{7}$ Baillon (2008) defines two events as exchangeable for an assessor if “...she is indifferent to permutations of their outcomes".

${ }^{8}$ We acknowledge a reviewer for spotting this possibility.
} 
priors, for each subject $i$, we simulate (1) the median estimates $S_{50}$ when she/he was provided with fixed lower $\left(S_{0}=0 \%\right)$ and upper bounds $\left(S_{100}=100 \%\right)$, (2) with hypothetical and symmetric lower $\left(S_{0}=20 \%\right)$ and upper bounds $\left(S_{100}=80 \%\right)$, (3) with hypothetical and left-shifted lower $\left(S_{0}=5 \%\right)$ and upper bounds $\left(S_{100}=80 \%\right)$, and with hypothetical and right-shifted lower $\left(S_{0}=20 \%\right)$ and upper bounds $\left(S_{100}=95 \%\right)$.

If simulated risk estimates do not differ from each other, then the provision of fixed boundaries do not affect subjects' choice behaviors and, hence, their risk estimates. Both WMP and SMP tests show that simulated risk estimates do not statistically differ from each other (Table 10). Thus, we conclude that, despite the provision of fixed boundaries rather than subjective ones, we still obtain reliable estimates.

\subsection{Regression Model and Results}

In this section we provide an additional regression model that further illustrates how the ownership and climate change effects, the subject's environmental attitudes, and their socio-economic characteristics shape subjective pest risks. The dependent variable (y) is the subjects' estimates of the percentage of damaged trees by the pine beetle, and all three elicited from each subject are used (i.e., $\mathrm{S}_{25}, \mathrm{~S}_{50}$, and $\mathrm{S}_{75}$ ).

Given that this dependent variable is a probability bounded by 0 and $1(0 \leq \mathrm{y} \leq 1)$, we should not estimate a simple OLS model unless we transform our dependent variable by using specific algorithms. Hence, we first create a new dependent variable by using an angular transformation, such as $y^{\prime}=\arcsin \sqrt{y}$. The transformed variable $y^{\prime}$ can now take any value and thus this allows us to use an OLS estimation procedure, Model 1, although there is not any underlying theoretical explanation for why one should use this strategy. 
An alternative and very popular way to handle this issue for a variable with 0,1 bounds consists of modeling the log-odds ratio as a linear function and then using a OLS estimation procedure on this ratio. In this alternative approach, we transform our dependent variable as follows, $y^{\prime \prime}=\ln [y /(1-y)]$, which is our Model 2. However, this procedure also has limitations. First, the estimates are biased if positive probabilities are associated with $y^{\prime \prime}=0$ or $y^{\prime \prime}=1$, and second, it does not allows analysts to directly infer the expected value, $E\left[y^{\prime \prime} \mid x\right]$.

Thus, because of limitations of Models 1 and 2, we also apply Papke and Woolridge's (1996) quasi-likelihood method based on a generalized linear models (GLM) framework. In this case, we do not need to transform our dependent variable, but we need to make assumptions on the distribution of our dependent variable and the relationship between our dependent and independent variables which is expressed by the link function. Given that our dependent variable tells us about the percentage of the forest that will be damaged and relative percentage that will be not damaged, we assume that it has a binomial distribution. Furthermore, in our Model 3, we assume that the link function is logistic (see Cameron and Trivedi, p. 149, 2005).

In these three models, we need to consider that each subject provides three risk estimates, one related to the first quartile of her/his $\operatorname{CDF}\left(\mathrm{S}_{25}\right)$, one to the median $\left(\mathrm{S}_{50}\right)$ estimate, and the last to the second quartile $\left(\mathrm{S}_{75}\right)$. Hence, we explain the variation in the dependent variable using clustering our sample at the subject level. This approach takes care of the potential correlation between responses that come from the same individual subject, while allowing for exploration of the effect of covariates on the risk responses.

Summarizing, we estimate the following three models: 


$$
\begin{aligned}
& \text { (1) } y_{i s}^{\prime}=\arcsin \sqrt{y}=\alpha+\beta X_{i s}+\varepsilon_{i s} \\
& \text { (2) } y_{i s}^{\prime \prime}=\ln [y /(1-y)]=\alpha+\beta X_{i s}+v_{i s} \\
& \text { (3) } y_{i s}=g\left(\alpha+\beta X_{i s}\right)+\eta_{i s}
\end{aligned}
$$

where $i=\{1,2, \ldots, 164\}$ indicates the subject and $s=\left\{S_{25}, S_{50}, S_{75}\right\}$ is the observation for each subject. The error terms differ, according to the specification of the dependent variable, and the $\alpha$ term represents an unobservable for the cluster group (each subject). In the third model above the dependent variable $y_{i s}$ has a binomial distribution and the link function corresponding to $g$ is a logit.

Factors shaping subjective risk are represented by a set of continuous and discrete variables (in the vector $\mathrm{X}$ ). Table 11 provides definitions, means, minima, and maxima for the explanatory variables. First, $R I S K_{-} P R$ is a continuous variable (between 0 and 100 percent) representing the subject's stated prior estimate of the risk (chance) that the pine beetle will destroy 10 percent of the forest during the period. However, subjects could decide to provide an estimated range for this prior, rather than a point estimate. The width of this range $(A M B)$ might be interpreted as a proxy for ambiguity (e.g., see discussion of the range of risk estimates and relations to ambiguity in risk in Riddel and Shaw, 2006; or Riddel 2011). We realize that the forest trips variable, FOR_VIS, is typically a choice, modeled as an endogenous variable in recreation demand models. However, for our model of subjects' reported damage estimates, we do not suspect that many factors that would explain a subject's damage estimate, and for which we have data, overlap much with those that explain taking trips. The variable TIMBER_LINK identifies subjects who are tied to timber industry, while $R U R A L$ subjects who originally comes from rural areas. 
As noted above, some subjects had ties to the timber industry and may under or overestimate perceived risks as compared to the subjects who have no direct stakes in the forests' well-being. In our sample, we have only eight subjects who are involved in timber production, but they have lower estimates than the others. On average, their estimates of variables $S_{25}, S_{50}$, and $S_{75}$ are 19.94, 21.94, and 28.49 percent as compared to $31.75,37.40,42.29$ percent for the others. We also observe that combining those few observations provided by subjects with stakes with the the pool without such stakes does not significantly influence the magnitude of the estimates of the variables $S_{25}, S_{50}$, and $S_{75}$. In fact, pooling all observations, the mean values of $S_{25}, S_{50}$, and $S_{75}$ are equivalent to $31.18,36.64$, and 41.61 percent. The discrepancy is less than 1 percent for all variables. Thus, it appears that, even if we assume that the subjects with stakes provide biased estimates, this does not significantly affect our overall results.

In addition two complete sets of dummy variables are used in estimation. The first of these is composed of indicators for all of the individual games, i.e., the exercises where the variable values for $S_{25}, S_{50}$, and $S_{75}$ are obtained. The second set is composed of indicator variables for the treatments: $\mathrm{T}_{\text {pu-nocc }}$ for "public-no climate change" treatment, $\mathrm{T}_{\mathrm{pr}-\text { nocc }}$ for "private-no climate change", $\mathrm{T}_{\mathrm{pu}-\mathrm{cc}}$ for "public-climate change”, $\mathrm{T}_{\mathrm{pr}-\mathrm{cc}}$ for "private-no climate change", $\mathrm{T}_{\mathrm{pu}}$ for "public-no climate change" used in within-subjects analysis and $\mathrm{T}_{\mathrm{pr}}$ for "private-no climate change" used in within-subjects analysis.

We estimate Models 1 and 2 using OLS, while we estimate Model 3 using the GLM approach described above. In all cases, we compute robust standard errors and cluster our observations at individual level as each subject provides three different observations. The regression results are reported in Table 12, and note that there is a 
distinct superiority of the GLM approach. We therefore focus on the results related to Model 3. The subject's prior estimate of the risk for 10 percent of the forest to be damaged negatively $\left(R I S K \_P R\right)$ influences the subject's estimates of forest damage (at the 1 percent significance level). Those with a larger initial prior have significantly lower estimates of damage after being given information on the current low level of pine beetle infestation in Texas forests later in the survey.

A larger ambiguity proxy $(A M B)$ related to the prior risk estimate indicates the subject is initially more uncertain than those who provide a point estimate or narrower width. This initial uncertainty appears to be significantly (at the 10 percent significance level) and positively related to the damage estimates obtained in the games, and this is consistent with reports in the literature that find that ambiguity may influence preferences (e.g., Baker et al., 2009).

Subjects who are personally tied to the timber industry (TIMB_LINK) and who are active forest recreationists (FOR_VIS) have damage estimates which are lower than other subjects, although significance is relatively weak here (at the 10 percent levels). This may be because they have a better knowledge of the actual low infestation level in Texas or because they have bet on the outcome they would like to experience in the future. This positive feeling about a future scenario is deemed as desirability bias in the psychological literature. As suggested earlier, perhaps actual forest users sought out forests that do not suffer from pine beetle problems and thus discount the possibility of extensive future damage. To explore potential endogeneity in FOR_VIS, we re-estimated the regression without it, but this had no affect on the other coefficients. We also tried substitution for the forest visits variable (FOR_VIS) with the more simple indication of forest use 
$\left(F O R \_U S E\right)^{9}$, but the discrete indicator coefficient was not significantly different from zero. The intensity of use captured in trips taken may encompass recent knowledge of the forests and their health. The other demographic and attitudinal variables had no significant effect on the dependent variable.

On the contrary, subjects who comes from rural areas $(R U R A L)$ have greater damage estimates than the others as they likely know the positive correlation between climatic variables (especially temperature, precipitation, and humidity) and the development of agricultural pests (at the $10 \%$ significance level), but they do not gain any utility from the fact that forest will be not damaged by the pine beetle.

According to our expectations, we found that damage estimates relative to the median $\left(\mathrm{S}_{50}\right)$ and second quartile $\left(\mathrm{S}_{75}\right)$ of individual CDFs are higher than those relative to the first quartile $\left(\mathrm{S}_{25}\right)$. Of course, this is consistent with the laws of probability theory.

Finally, we econometrically test whether damage observations differ across treatment groups. This analysis allows us to statistically test again the "ownership/access effect" and the "climate change effect" relying on a larger number of observations. We consider the treatment group "private forest" in the within-subjects analysis as our reference group. This treatment group provided the lowest mean value of damaged estimates (see Table 2).

Analyzing the "ownership/access effect" in the within-subjects treatment we found that subjects perceive forest damage to be greater in public forests than in private ones (at the $10 \%$ significance level). This is consistent with our results from nonparametric testing. Interestingly, when subjects are asked only to estimate damages for private forests as it occurs in the "private forest-no climate change information"

\footnotetext{
${ }^{9}$ Forest use (FOR_USE) is a discrete indicator variable with two levels ( $1=$ forest users, $0=$ otherwise).
} 
treatment, they show higher risk estimates than when people are asked to complete the same task by comparing forest damages in private and public forests as it occurs in the within-subjects treatment (at the 5\% significance level). Furthermore, subjects' estimates keep on increasing when subjects are asked only to estimate damages for public forests as it occurs in the "public forest-no climate change information" treatment (at the 5\% significance level).

Finally, we show that informing subjects that climate change is the source of the pine beetle infestation increase their estimates of damages in both private and public forests (both at the $1 \%$ significance level) as compared to our reference group. This support the "climate change" effect we have already shown in our nonparametric testing.

\section{Discussion}

We obtain mixed results on the significance of forest access and climate change information on risk estimates. The nature of the treatment matters (i.e., whether we consider between-subjects or within-subjects). Subjects do not seem to care about the public or private nature of forests in the between-subjects analysis maybe because both public and private forest owners face the same risk and have the same management options. However, but when presented with both types of forests in the within-subjects analysis, the same subject, on average has a higher estimate of risk when publicly accessed forests are considered than when private ones are. This may be due to heterogeneity across subjects, but could also be due to the different treatment process.

To explore the first possibility, Table 13 provides some summary statistics for variables that might differ for subjects between treatment groups. These casually suggest that differing results for the between versus within-subjects analyses are not caused by 
differences in the composition of the subject sample in terms of either connections to family or friends in the timber industry, or extent of their use of public forest (see rows 15 to 22 of Table 13). The percentage of all of our subjects with a relationship to someone in the timber industry is very low both in the between- and within-subjects samples, ranging from 0 to 6 percent. In contrast, the percentage of subjects who used public forests is relatively high in both samples, ranging from 56 to 71 percent. The average number of recreational visits-subjects took during the last year ranges from 2 to 6 trips or visits. A MW test does not detect significant statistical differences for the between-subjects versus within-subjects treatment groups in terms of the distribution of their trips or visits.

However, one possible explanation for the difference in damage risk perceptions for the within-subjects treatment pertains to a very low degree of familiarity with the pine beetle problem, as is evident in rows 1 to 8 of Table 13. Our subjects' uniformly limited knowledge about the pine beetle problem probably increases the perception of a difference between the pest risk in public and private forests, only if, and when the subject can make a direct comparison between the two cases, as occurs in the within subjects treatment.

Evaluating the treatment groups separately, the distributions of the dependent variables evaluated at each of the three underlying probabilities are not significantly different when climate change is mentioned for publicly accessed forests, but they are for private forests, at two points $\left(S_{25}\right.$ and $\left.S_{75}\right)$. However, when we pool all the observations for the public and private forests for both when climate change is mentioned and when it is not, there is a statistically significant difference between the distributions for all three 
evaluated points $\left(\mathrm{S}_{25}, \mathrm{~S}_{50}\right.$, and $\left.\mathrm{S}_{75}\right)$ : risks are higher when climate change is mentioned. Pooling appears justified because risk perceptions are not influenced by the public or private nature of the forest in the between-subjects investigations.

Our results support the "home team betting" hypothesis (Viscusi and Zeckhauser 2006), mentioned above. Contrary to our expectations, many respondents are confident that climate change is already happening and that it will also happen in the future. In particular, the majority of the subjects in the "climate change" treatment groups agree with statements such as "climate change is already happening" and "climate change will happen in the future," as shown in rows 10 to 13 of Table 13. The provision of information on climate change being the source of pine beetle infestation to these people increases their subjective perceptions of pest risk.

\section{Conclusions}

Although risks are a fundamentally important part of climate change or global warming, science-based risk estimates are characterized by very wide confidence intervals. This makes subjective or perceived risks important in assessing decisions that must be made now in order to potentially affect outcomes in the future. Our analysis is focused on the relationship between potential climate change impacts and pine beetle damage on forests, admittedly a somewhat small part of the overall climate change or global warming picture. We find some support in the analysis that climate change information affects individuals' risk perceptions and it may be that this has broader implications for other risky climate change impacts. Our method in the risk elicitation is a rediscovered one in the literature, and whether it is incentive compatible is still in 
question (see Abdelloui et al., 2011), but the results show a high degree of internal consistency for subjects.

Much more could be done to improve on what we have here. If a consistent prior is asked of respondents, the EM framework could perhaps be closely tied to Viscusi's (1989) Prospective Reference Theory, wherein a simple Bayesian approach motivates updating of estimates based on information

\section{Acknowledgments}

We thank Brit Grosskopf and Yvette Zhang for help on implementing this experiment, and Jana Lambert for help organizing the sessions at the Economics Research Laboratory at Texas A\&M University. Addressing two anonymous reviewers' sets of comments have greatly improved the paper. We also appreciate comments on an earlier draft of the paper and/or the EM approach from Trudy Cameron, Therese Grijalva, Tom Holmes, Rodolfo Nayga, Christian Vossler, Richard Woodward, and several seminar and conference participants. Shaw acknowledges funding from the U.S.D.A. Regional/Hatch project. 


\section{References}

Abdellaoui, M., Baillon, A., Placedo, L., Wakker, P.P., 2011. The Rich Domain of Uncertainty: Source Functions and Their Experimental Implementation. American Economic Review 101, 695-723.

Andersen, S., Fountain, J., Harrison, G.W., Rutström, E.E., 2010. Estimating Subjective Probabilities. Working Paper 09-01, Department of Economics, College of Business Administartion, University of Central Florida.

Baillon, A. 2008. Eliciting Subjective Probabilities Through Exchangeable Events: an Advantage and a Limitation. Decision Analysis 5(2), 76-87.

Baker, J., Shaw, W.D., Riddel, M., Woodward, R.T., 2009. Explaining Changes in Subjective Hurricane Risks as Time Passes: An Analysis of a Sample of Katrina Evacuees. Journal of Risk Research 12(1), 59-74.

Bostrom, A., Morgan, M.G., Fischhoff, B., Read, D. 1994. What do people know about global climate change. Risk Analysis 14(6), 959-970.

Botzen, W.J.W., Aerts, J.C.J.H., van den Bergh, J.C.J.M., 2009. Dependence of flood risk perceptions on socioeconomic and objective risk factors. Water Resource Research, 45, W10440, doi:10.1029/2009WR007743.

Bulte, E., Gerking, S., List, G.A., de Zeeuw, A., 2005. The effect of varying the causes of environmental problems on stated WTP values: Evidence from a field survey. Journal of Environmental Economics and Management 49, 330-42.

Cameron, A.C. and P.K. Trivedi. 2005. Microeconometrics: Methods and Applications. New York: Cambridge University Press. 
Carlson, G.A., 1978. A decision theoretic approach to crop disease prediction and control. American Journal of Agricultural Economics 52(2), 216-223.

Chew S.H., Sagi, J., 2006. Event exchangeability: Probabilistic sophistication without continuity or monotonicity. Econometrica 74, 771-786.

Corso P.S., Hammit J.K., Graham J.D., 2001. Valuing mortality-risk reduction : Using visual aids to improve the validity of contingent valuation. Journal of Risk and Uncertainty 23, 165-184.

de Finetti, B., 1937. La prévision: Ses lois logiques, ses sources subjectives. Annales de l'IHP 7, 1-68.

Dominitz, J. and Manski, C., 1997. Using Expectations Data to Study Subjective Income Expectations. Journal of the American statistical Association, 92, 855-867.

Dreze, J.H., 1987. Essays on Economic Decision Under Uncertainty. Cambridge University Press, Cambridge, UK.

Fiore, S.M., Harrison, G.W., Hughes, C.E., Ruström, E.E., 2009. Virtual experiments and environmental policy. Journal of Environmental Economics and Management 57 (1), 65-86.

Fox, C.R., Tversky, A., 1998. A belief-based account of decision under uncertainty. Management Science 44, 879-895.

Gan, J., 2004. Risk and damage of southern pine beetle outbreaks under global climate change. Forest Ecology and Management 191, 61-71.

Gegax, D., Gerking, S., Schulze, W., 1991. Perceived Risk and the Marginal Value of Safety. The Review of Economics and Statistics 73(4), 589-596. 
Gigerenzer, G., Hoffrage, U., 1995. How to improve Bayesian reasoning without instruction - frequency formats. Psychological Review 102 684-704.

Hammit, J.K., Graham J.D., 1999. Willingness to Pay for Health Protections: Inadequate Sensitivity to Probability? Journal of Risk and Uncertainty, 8: 33-62.

Holmes, T.P., 1991. Price and Welfare Effects of Catastrophic Forest Damage from Southern Pine Beetle Epidemics. Forest Science 37(2), 500-516.

IPCC, 2007. Climate Change 2007: Synthesis Report. Contribution of Working Groups I, II and III to the Fourth Assessment Report of the Intergovernmental Panel on Climate Change [Core Writing Team, Pachauri, R.K and Reisinger, A. (eds.)]. IPCC, Geneva, Switzerland, 104 pp.Jakus, P.M., Shaw, W.D., Nguyen, T.N., Walker, M., 2009. Risk Perceptions of Arsenic in Tap Water and Bottled Water Consumption. Water Resource Research 45, Doi:10.1029/2008WR007427

Karni, E., 1993. A Definition of Subjective Probabilities with State-Dependent Preferences. Econometrica 61 (1/January): 187-98.

Karni, E., 2009. A Mechanism for Eliciting Probabilities. Econometrica 77 (2/March): 603-606.

Kilka, M., Weber, M., 2001. What Determines the Shape of the Probability weighting function under uncertainty. Management Science 47, 1712-1726.

Leiserowitz, A., 2005. American Risk Perceptions: Is Climate Change Dangerous? Risk Analysis 25(6): 1433-1442.

Leiserowitz, A., 2006. Climate change risk perception and policy preferences: The role of affect, imagery, and values. Climatic Change 77, 45-72

Manski, C., 2004. Measuring Expectations. Econometrica 72 (5/September) : 1329-1376. 
Nguyen, T.N., Jakus, P.M., Riddel, M., Shaw, W.D., 2010. An Empirical Model of Perceived Mortality Risks for Selected United States Arsenic Hot Spots. Risk Analysis 30(10), 1550-1562.

Pregerning, M., 2002. Perceptions, Not facts: How Forestry Professionals Decide on the Restoration of Degraded Forest Ecosystems. Journal of Environmental Planning and Management 45(1): 25-38, DOI: 10.1080/09640560120100178.

Pingali, P.I., Carlson, G.A., 1985. Human capital, adjustments in subjective probabilities and the demand for pest controls. American Journal of Agricultural Economics 67 (4), 853-861.

Riddel, M., 2011. Uncertainty and Measurement Error in Welfare Models for Risk Changes. Journal of Environmental Economics and Management 61: 341-54.

Riddel, M., Shaw, W.D., 2006. A Theoretically-Consistent Empirical Non-Expected Utility Model of Ambiguity: Nuclear Waste Mortality Risk and Yucca Mountain. Journal of Risk and Uncertainty 32(2), 131-150.

Savage, L. J., 1971. "Elicitation of Personal Probabilities and Expectations," Journal of the American Statistical Association, 66, 783-801.

Shaw, W.D., Woodward, R.T., 2008. On Why Environmental and Resource Economists Should Care about Non-Expected Utility Models. Resource and Energy Economics 30, 66-89.

Siegrist, M., Gutsher, H., 2006. Flooding Risks: A comparison of Lay people's Perceptions and Expert's Assessments in Switzerland. Risk Analysis, 26(4), 971979. 
Spetzler, C.S., Stael Von Holstein, C.-A.S., 1975. Probability encoding in decision analysis. Management Science 22, 340-358.Tversky, A., Fox, C.R., 1995. Weighing risk and uncertainty. Psychological Review 102, 269-283.

Tversky, A., Kahneman, D., 1992. Advances in prospect theory: Cumulative representation of uncertainty. Journal of Risk and Uncertainty 5, 297-323.

Viscusi, W.K. 1989. Prospective Reference Theory: Toward an Explanation of the Paradoxes. Journal of Risk and Uncertainty 2: 235-264.

Viscusi, W.K., 1990. Do Smokers Underestimate Risks. Journal of Political Economics 98(6), 1253-69.

Viscusi, W.K., Zeckhauser, R.J., 2006. The perception and valuation of the risks of climate change: A rational and behavioral blend. Climatic Change 77, 151-177.

Visschers, V.H.M., Meertens R.M., Passchier W.W.F., de Vries, N.N.K., 2009. Probability Information in Risk Communication: A Review of the Research Literature. Risk Analysis, 29, 267-287.

Wakker P., Deneffe D., 1996. Eliciting von Neumann-Morgenstern Utilities When Probabilities are Distorted or Unknown. Management Science, 42(8), 1131-1150. Weber, E.U., 2006. Experienced-based and description-based perceptions of long-term risk: Why global warming does not scare us (yet). Climatic Change 77, 103-120. 


\begin{tabular}{|c|c|c|c|}
\hline Session & Treatment & Type & Description \\
\hline 1 & $\begin{array}{l}\text { Public Forest - } \\
\text { No Climate Change }\end{array}$ & $\begin{array}{l}\text { Between } \\
\text { Subjects }\end{array}$ & $\begin{array}{l}\text { Subjects play the EM considering a public forest and } \\
\text { having no information on climate change }\end{array}$ \\
\hline 2 & $\begin{array}{l}\text { Private Forest - } \\
\text { No Climate Change }\end{array}$ & $\begin{array}{l}\text { Between } \\
\text { Subjects }\end{array}$ & $\begin{array}{l}\text { Subjects play the EM considering a private forest and } \\
\text { having no information on climate change }\end{array}$ \\
\hline 3 & $\begin{array}{l}\text { Public Forest - } \\
\text { Climate Change }\end{array}$ & $\begin{array}{l}\text { Between } \\
\text { Subjects }\end{array}$ & $\begin{array}{l}\text { Subjects play the EM considering a public forest and } \\
\text { having information on climate change }\end{array}$ \\
\hline 4 & $\begin{array}{l}\text { Private Forest - } \\
\text { Climate Change }\end{array}$ & $\begin{array}{l}\text { Between } \\
\text { Subjects }\end{array}$ & $\begin{array}{l}\text { Subjects play the EM considering a private forest and } \\
\text { having information on climate change }\end{array}$ \\
\hline 5 & $\begin{array}{l}\text { Private\&Public Forest - } \\
\text { No Climate Change }\end{array}$ & $\begin{array}{l}\text { Within } \\
\text { Subjects }\end{array}$ & $\begin{array}{l}\text { Subjects play the EM considering both public and } \\
\text { private forests, but having no information on climate } \\
\text { change }\end{array}$ \\
\hline
\end{tabular}

Table 2 Summary statistics of elicited percentages of damaged and killed trees by the pine beetle in the period between 2010 and 2050 for each treatment group.

\begin{tabular}{|c|c|c|c|c|c|c|c|c|c|c|}
\hline \multirow{2}{*}{ Treatment } & \multirow{2}{*}{ Obs. } & \multicolumn{3}{|c|}{ Mean } & \multicolumn{3}{|c|}{ Median } & \multicolumn{3}{|c|}{ Std. dev. } \\
\hline & & $\mathbf{S}_{25}$ & $S_{50}$ & $\mathbf{S}_{75}$ & $S_{25}$ & $S_{50}$ & $S_{75}$ & $S_{25}$ & $S_{50}$ & $\mathbf{S}_{75}$ \\
\hline $\begin{array}{l}\text { Public-no climate } \\
\text { change }^{\mathrm{a}}\end{array}$ & 38 & 30.8 & 35.8 & 40.9 & 26.5 & 34.5 & 37.0 & 22.2 & 23.6 & 25.3 \\
\hline $\begin{array}{l}\text { Private-no climate } \\
\text { change }^{\mathrm{a}}\end{array}$ & 43 & 27.0 & 33.0 & 37.5 & 24.0 & 28.0 & 30.5 & 20.5 & 22.4 & 23.6 \\
\hline $\begin{array}{l}\text { Public-no climate } \\
\text { change }^{\text {b }}\end{array}$ & 30 & 29.0 & 33.9 & 39.2 & 19.5 & 22.0 & 30.0 & 25.9 & 27.6 & 28.7 \\
\hline $\begin{array}{l}\text { Private-no climate } \\
\text { change }^{b}\end{array}$ & 30 & 18.6 & 23.5 & 29.5 & 14.0 & 19.0 & 22.5 & 18.0 & 20.9 & 25.9 \\
\hline $\begin{array}{l}\text { Public-climate } \\
\text { change }^{\mathrm{a}}\end{array}$ & 21 & 40.6 & 49.4 & 53.8 & 39.0 & 53.0 & 55.0 & 24.7 & 25.4 & 25.2 \\
\hline $\begin{array}{l}\text { Private-climate } \\
\text { change }^{\mathrm{a}}\end{array}$ & 32 & 38.1 & 42.7 & 48.1 & 39.0 & 41.0 & 44.0 & 23.0 & 24.0 & 23.7 \\
\hline Climate change $^{\mathrm{a}, \mathrm{c}}$ & 53 & 39.1 & 45.4 & 50.4 & 39.0 & 41.0 & 47.0 & 23.5 & 24.5 & 24.2 \\
\hline No climate change ${ }^{\mathrm{a}, \mathrm{d}}$ & 81 & 28.8 & 34.3 & 39.1 & 26.5 & 28.0 & 35.0 & 21.3 & 22.9 & 24.3 \\
\hline
\end{tabular}

\footnotetext{
${ }^{\text {a }}$ Between-subjects analysis

${ }^{\mathrm{b}}$ Within-subjects analysis

"Pooling "Public-climate change" + "Private-climate change" samples

dPooling "Public-no climate change" + "Private-no climate change" samples
} 
Table 3 Kolmogorov-Smirnov test for comparing elicited percentages of damaged and killed trees between "public-no climate change" and "private-no climate change".

\begin{tabular}{lr}
\hline $\mathbf{H}_{\mathbf{0}}$ & P-value \\
\hline Distribution $\mathrm{S}_{25, \text { pu- nocc }}=$ Distribution $\mathrm{S}_{25, \text { pr-nocc }}$ & .970 \\
Distribution $\mathrm{S}_{50, \text { pu-nocc }}=$ Distribution $\mathrm{S}_{50, \text { pr-nocc }}$ & .998 \\
Distribution $\mathrm{S}_{75, \text { pu-nocc }}=$ Distribution $\mathrm{S}_{75, \text { pr-nocc }}$ & .945 \\
\hline
\end{tabular}

pu-nocc is the "public-no climate change" treatment in the between-subjetcs analysis

pr-nocc is the "private-no climate change" treatment in the between-subjetcs analysis

Table 4 Kolmogorov-Smirnov test for comparing elicited percentages of damaged and killed trees between "public-climate change" and "private-climate change"

\begin{tabular}{lr}
\hline $\mathbf{H}_{\mathbf{0}}$ & P-value \\
\hline Distribution $\mathrm{S}_{25, \text { pu-cc }}=$ Distribution $\mathrm{S}_{25, \mathrm{pr}-\mathrm{cc}}$ & .895 \\
Distribution $\mathrm{S}_{50, \text { pu-cc }}=$ Distribution $\mathrm{S}_{50, \mathrm{pr}-\mathrm{cc}}$ & .891 \\
Distribution $\mathrm{S}_{75, \mathrm{pu}-\mathrm{cc}}=$ Distribution $\mathrm{S}_{75, \mathrm{pr}-\mathrm{cc}}$ & .973 \\
\hline
\end{tabular}

pu-cc is the "public-climate change" treatment in the between-subjects analysis pr-cc is the "private-climate change" treatment in the between-subjects analysis

Table 5 Wilcoxon matched-pairs signed-ranks test and Sign test of matched pairs for comparing elicited percentages of damaged and killed trees between "public" and "private".

\begin{tabular}{|c|c|c|c|}
\hline \multicolumn{2}{|c|}{ Wilcoxon matched-pairs signed-ranks test } & \multicolumn{2}{|l|}{ Sign test of matched pairs } \\
\hline $\mathbf{H}_{\mathbf{0}}$ & Prob $>|z|$ & $\mathbf{H}_{\mathbf{0}}$ & Prob $>|z|$ \\
\hline Median $S_{25, p u}=$ Median $S_{25, p r}$ & .0689 & Median $S_{25, \text { pu }}=$ Median $S_{25, p r}$ & .3075 \\
\hline Median $S_{50, p u}=$ Median $S_{50, p r}$ & .0697 & Median $S_{50, p u}=$ Median $S_{50, p r}$ & .2100 \\
\hline Median $S_{75, p u}=$ Median $S_{75, p r}$ & .0579 & Median $S_{75, p u}=$ Median $S_{75, p r}$ & .0466 \\
\hline
\end{tabular}

pu is the "public-no climate change" treatment in the within-subjetcs analysis $\mathrm{pr}$ is the "private-no climate change" treatment in the within-subjetcs analysis 
Table 6 Kolmogorov-Smirnov test for comparing elicited percentages of damaged and killed trees between "public-no climate change" and "publicclimate change"

\begin{tabular}{lr}
\hline $\mathbf{H}_{\mathbf{0}}$ & P-value \\
\hline Distribution $\mathrm{S}_{25, \mathrm{pu}-\mathrm{cc}}=$ Distribution $\mathrm{S}_{25, \mathrm{pr}-\mathrm{cc}}$ & .250 \\
Distribution $\mathrm{S}_{50, \mathrm{pu}-\mathrm{cc}}=$ Distribution $\mathrm{S}_{50, \mathrm{pr}-\mathrm{cc}}$ & .230 \\
Distribution $\mathrm{S}_{75, \mathrm{pu}-\mathrm{cc}}=$ Distribution $\mathrm{S}_{75, \mathrm{pr}-\mathrm{cc}}$ & .106 \\
\hline
\end{tabular}

Table 7 Kolmogorov-Smirnov test for comparing elicited percentages of damaged and killed trees between "private-no climate change" and "privateclimate change"

\begin{tabular}{lr}
\hline $\mathbf{H}_{\mathbf{0}}$ & P-value \\
\hline Distribution $\mathrm{S}_{25, \text { pu-cc }}=$ Distribution $\mathrm{S}_{25, \mathrm{pr}-\mathrm{cc}}$ & .0171 \\
Distribution $\mathrm{S}_{50, \mathrm{pu}-\mathrm{cc}}=$ Distribution $\mathrm{S}_{50, \mathrm{pr}-\mathrm{cc}}$ & .1563 \\
Distribution $\mathrm{S}_{75, \mathrm{pu}-\mathrm{cc}}=$ Distribution $\mathrm{S}_{75, \mathrm{pr}-\mathrm{cc}}$ & .0661 \\
\hline
\end{tabular}

Table 8 Kolmogorov-Smirnov test for comparing elicited percentages of damaged and killed trees between "no climate change" and "climate change".

\begin{tabular}{lr}
\hline $\mathbf{H}_{\mathbf{0}}$ & P-value \\
\hline Distribution $\mathrm{S}_{25, \text { no cc }}=$ Distribution $\mathrm{S}_{25, \mathrm{cc}}$ & .0072 \\
Distribution $\mathrm{S}_{50, \text { nocc }}=$ Distribution $\mathrm{S}_{50, \mathrm{cc}}$ & .0344 \\
Distribution $\mathrm{S}_{75, \text { nocc }}=$ Distribution $\mathrm{S}_{75, \mathrm{cc}}$ & .0063 \\
\hline $\begin{array}{l}\text { cc is derived by pooling "Public-climate change" plus "Private climate change" } \\
\text { samples } \\
\text { nocc is derived by pooling "Public-no climate change" plus "Private-no climate } \\
\text { change" samples }\end{array}$
\end{tabular}




\begin{tabular}{lc}
\hline \multicolumn{2}{l}{ Table 9 Paired t test for consistency } \\
\hline $\mathbf{H}_{\mathbf{0}}$ & $\mathbf{t}$ \\
\hline$s^{\prime \prime}=S_{25}$ & $9.6823^{*}$ \\
$s^{\prime \prime}=S_{50}$ & -3.9213 \\
$\left|S_{50}-s^{\prime}\right|=\left|S_{25}-s^{\prime \prime}\right|$ & $15.3148^{*}$ \\
$S_{50}=S_{50}$ & -0.5909 \\
\hline
\end{tabular}

Table 10 Wilcoxon matched-pairs signed-ranks test and Sign test of matched pairs for comparing elicited percentages of damaged and killed trees using fixed boundaries, hypothetical and symmetric boundaries, hypothetical and left-shifted boundaries, and hypothetical and rightshifted boundaries.

\begin{tabular}{|c|c|c|c|}
\hline \multicolumn{2}{|c|}{ Wilcoxon matched-pairs signed-ranks test } & \multicolumn{2}{|l|}{ Sign test of matched pairs } \\
\hline $\mathbf{H}_{\mathbf{0}}$ & Prob $>|z|$ & $\mathbf{H}_{\mathbf{0}}$ & $\operatorname{Prob}>|z|$ \\
\hline Median $S_{50, f x}=$ Median $S_{25, h s}$ & .9435 & Median $S_{50, \mathrm{fx}}=$ Median $S_{25, \text { hs }}$ & .1000 \\
\hline Median $S_{50, \text { fx }}=$ Median $S_{50, \text { hal }}$ & .9719 & Median $S_{50, \mathrm{fx}}=$ Median $\mathrm{S}_{50, \text { har }}$ & .1000 \\
\hline Median $S_{75, \text { fx }}=$ Median $S_{75, \text { har }}$ & .6220 & Median $S_{75, \mathrm{fx}}=$ Median $S_{75, \text { hal }}$ & .1000 \\
\hline
\end{tabular}

fx are risk estimates obtained by using fixed boundaries $S_{0}=0 \%$ and $S_{100}=100 \%$ hs are risk estimates obtained by using fixed boundaries $S_{0}=20 \%$ and $S_{100}=80 \%$ hal are risk estimates obtained by using fixed boundaries $S_{0}=5 \%$ and $S_{100}=80 \%$ har are risk estimates obtained by using fixed boundaries $S_{0}=20 \%$ and $S_{100}=95 \%$ 


\begin{tabular}{|c|c|c|c|c|c|}
\hline Variable & Definition & Mean & Std.Dev & Min. & Max. \\
\hline$\% \mathrm{DAM}$ & $\begin{array}{l}\text { Percentage of damaged trees in the } \\
\text { period } 2010-2050^{\text {a }}\end{array}$ & 0.36 & 0.25 & 0.10 & 0.99 \\
\hline \%DAM_ANG & Angular Transformation & 0.51 & 0.19 & 0.09 & 0.84 \\
\hline \%DAM_LOR & Log-Odds ratio Transformation & -0.76 & 1.57 & -4.59 & 5.29 \\
\hline RISK_PR & $\begin{array}{l}\text { Prior risk estimate for } 10 \% \text { of forest } \\
\text { damaged during } 2010-2050\end{array}$ & 0.53 & 0.22 & 0.00 & 0.10 \\
\hline AMB & $\begin{array}{l}\text { Width of range for those who provide a } \\
\text { range rather than point estimate }\end{array}$ & 0.52 & 0.17 & 0.00 & 0.85 \\
\hline GW-PAST & $\begin{array}{l}\text { Agreement with scientists about global } \\
\text { warming in the past (at } 5 \text { levels) }\end{array}$ & 2.42 & 1.48 & 0.00 & 4.00 \\
\hline GW-FUT & $\begin{array}{l}\text { Agreement with scientists about global } \\
\text { warming in the future (at } 5 \text { levels) }\end{array}$ & 2.18 & 1.22 & 0.00 & 4.00 \\
\hline AC_KN & $\begin{array}{l}\text { Attendance at seminars about climate } \\
\text { change and pest }\end{array}$ & .27 & .44 & 0.00 & 1.00 \\
\hline $\mathrm{MC} \_\mathrm{KN}$ & $\begin{array}{l}\text { Viewer or reader of scientific programs } \\
\text { or articles about climate change and pest }\end{array}$ & .43 & .49 & 0.00 & 1.00 \\
\hline TIMB-LINK & Tie (family or friend) to Timber industry ${ }^{\mathrm{c}}$ & 0.05 & 0.21 & 0.00 & 1.00 \\
\hline FOR_VIS & Number of visits to forest in past year & 2.19 & 5.37 & 0.00 & 60.00 \\
\hline RURAL & Coming from a rural area & .17 & .38 & 0.00 & 1.00 \\
\hline AGE & Age in years & 20.57 & 1.26 & 18.00 & 26.00 \\
\hline FEMALE & $=1$ if female,$=0$ otherwise & .54 & .50 & 0.00 & 1.00 \\
\hline INCOME & Annual household income (at 18 levels) & 7.66 & 7.21 & 0.00 & 17.00 \\
\hline $\mathrm{S}_{25}$ & $\begin{array}{l}\text { Damaged estimates related to the first } \\
\text { quartile risk estimate }\end{array}$ & 0.33 & .47 & 0.00 & 1.00 \\
\hline $\mathrm{S}_{50}$ & $\begin{array}{l}\text { Damaged estimates related to the } \\
\text { Median risk estimate }\end{array}$ & 0.33 & .47 & 0 & 1.00 \\
\hline $\mathrm{S}_{75}$ & $\begin{array}{l}\text { Damaged estimates related to the } \\
\text { Second quartile risk estimate }\end{array}$ & 0.33 & .47 & 0 & 1.00 \\
\hline $\mathrm{T}_{\text {pu-nocc }}$ & First experimental treatment & 0.15 & 0.35 & 0 & 1.00 \\
\hline $\mathrm{T}_{\text {pr-nocc }}$ & Second experimental treatment & 0.16 & 0.37 & 0 & 1.00 \\
\hline $\mathrm{T}_{\mathrm{pu}-\mathrm{cc}}$ & Third experimental treatment & 0.13 & 0.33 & 0 & 1.00 \\
\hline $\mathrm{T}_{\mathrm{pr}-\mathrm{cc}}$ & Fourth experimental treatment & 0.19 & 0.39 & 0 & 1.00 \\
\hline $\mathrm{T}_{\mathrm{pu}}$ & Fifth experimental treatment & 0.18 & 0.38 & 0 & 1.00 \\
\hline $\mathrm{T}_{\mathrm{pr}}$ & Sixth experimental treatment & 0.18 & 0.38 & 0 & 1.00 \\
\hline
\end{tabular}


Table 12 Regression results of Model 1, 2, and 3

\begin{tabular}{|c|c|c|c|}
\hline & Model 1 & Model 2 & Model 3 \\
\hline $\begin{array}{l}\text { Estimation } \\
\text { procedure: }\end{array}$ & $\begin{array}{r}\text { OLS with robust } \\
\text { stand. err. and } \\
\text { clustering }\end{array}$ & $\begin{array}{r}\text { OLS with robust stand. } \\
\text { err. and clustering }\end{array}$ & $\begin{array}{r}\text { GLM with binomial } \\
\text { fam. func. and } \\
\text { logistic link func. }\end{array}$ \\
\hline $\begin{array}{l}\text { Dependent } \\
\text { Variable: }\end{array}$ & $\arcsin \sqrt{ } \%$ DAM & $\log [\% \mathrm{DAM} /(1-\% \mathrm{DAM})]$ & \%DAM \\
\hline RISK_PR & $-.1433^{*}$ & $-1.2570 * *$ & $-1.0106 *$ \\
\hline AMB & $.1259 * *$ & .7139 & $.6030 * * *$ \\
\hline GW_PAST & .0042 & .0943 & .0441 \\
\hline GW_FUT & -.0015 & -.0907 & -.0285 \\
\hline AC_KN & .0260 & .1538 & .1532 \\
\hline MC_KN & .0204 & .2380 & .1394 \\
\hline TIMB_LINK & -.0710 & -.7577 & $-.4842 * * *$ \\
\hline FOR_VIS & -.0017 & -.0160 & $-.0153 * * *$ \\
\hline RURAL & $.0647 * * *$ & .5371 & $.4041 * * *$ \\
\hline AGE & -.0025 & -.0238 & -.0197 \\
\hline FEMALE & -.0332 & -.2634 & -.2515 \\
\hline INCOME & .0018 & .0177 & .0115 \\
\hline Prob_S $S_{50}$ & $.0456^{*}$ & $.3975^{*}$ & $.2571 *$ \\
\hline Prob_S 75 & $.0831 *$ & $.7661^{*}$ & $.4777 *$ \\
\hline $\mathrm{T}_{\text {pu-nocc }}$ & $.1346^{*}$ & $.9950^{*}$ & $.7069 * *$ \\
\hline $\mathrm{T}_{\text {pr-nocc }}$ & $.1040 * *$ & $.7695 * *$ & $.5810 * *$ \\
\hline $\mathrm{T}_{\mathrm{pu}-\mathrm{cc}}$ & $.1937 *$ & $1.5153^{*}$ & $1.1245^{*}$ \\
\hline $\mathrm{T}_{\mathrm{pr}-\mathrm{cc}}$ & $.1597 *$ & $1.1892 *$ & $.9069 *$ \\
\hline $\mathrm{T}_{\mathrm{pu}}$ & $.0815 * * *$ & $.7122 * * *$ & $.5201 * * *$ \\
\hline Cons. & $.4673 * * *$ & -1.0511 & -.6534 \\
\hline $\mathrm{F}$ & $15.0300 *$ & $10.6200 *$ & - \\
\hline R-squared & .2277 & .2253 & - \\
\hline Log P.Likel. & - & - & -226.83 \\
\hline
\end{tabular}

$* p<.01, * * p<.05, * * * p<.10$ 
Table 13 Responses on key explanatory variables

\begin{tabular}{lccccc}
\hline $\begin{array}{l}\text { Treatment } \\
\text { Group }\end{array}$ & \multicolumn{5}{l}{$\begin{array}{l}\text { Degree of familiarity with the pine beetle risk issue: Percentage of treatment } \\
\text { group responding in category }\end{array}$} \\
\hline & $\mathbf{1}$ & $\mathbf{2}$ & $\mathbf{3}$ & $\mathbf{4}$ & $\mathbf{5}$ \\
$1 \mathrm{Pu}-$ cocc $^{\mathrm{a}}$ & 88 & 8 & 4 & 0 & 0 \\
$2 \mathrm{Pri}-$ nocc $^{\mathrm{a}}$ & 93 & 4 & 4 & 0 & 0 \\
$3 \mathrm{Pu}-\mathrm{cc}^{\mathrm{a}}$ & 85 & 10 & 5 & 0 & 0 \\
$4 \mathrm{Pr}-\mathrm{cc}^{\mathrm{a}}$ & 91 & 6 & 3 & 0 & 0 \\
$5 \mathrm{Pu}$ & 74 & 20 & 6 & 0 & 0 \\
$6 \mathrm{Pr}^{\mathrm{b}}$ & 74 & 20 & 6 & 0 & 0 \\
\hline
\end{tabular}

Agreement with the statement that Climate Change will Happen in the Future: Percentage of group responding in category ${ }^{\mathrm{d}}$

\begin{tabular}{|c|c|c|c|c|c|}
\hline & 1 & 2 & 3 & 4 & 5 \\
\hline $3 \mathrm{Pu}-\mathrm{cc}^{\mathrm{a}}$ & 0 & 33 & 24 & 33 & 10 \\
\hline \multirow[t]{3}{*}{$4 \operatorname{Pr}-\mathrm{cc}^{\mathrm{a}}$} & 9 & 19 & 22 & 34 & 16 \\
\hline & \multicolumn{5}{|c|}{$\begin{array}{l}\text { Percentage of Group with Private Forest Connection; Percentage Who Use Public } \\
\text { Forests, and Average Number of recreational visits to Public Forests (last year) }\end{array}$} \\
\hline & \multicolumn{2}{|c|}{$\begin{array}{l}\text { Private Forest } \\
\text { Connection }\end{array}$} & $\begin{array}{l}\text { Public Forest } \\
\text { Users }\end{array}$ & \multicolumn{2}{|c|}{$\begin{array}{c}\text { Average Recreational } \\
\text { Visits }\end{array}$} \\
\hline $1 \mathrm{Pu}-\operatorname{nocc}^{\mathrm{a}}$ & \multicolumn{2}{|c|}{0} & 71 & \multicolumn{2}{|c|}{2} \\
\hline 2 Pri-nocc ${ }^{\mathrm{a}}$ & \multicolumn{2}{|c|}{7} & 56 & \multicolumn{2}{|c|}{6} \\
\hline $3 \mathrm{Pu}-\mathrm{cc}^{\mathrm{a}}$ & \multicolumn{2}{|c|}{0} & 57 & \multicolumn{2}{|c|}{3} \\
\hline $4 \operatorname{Pr}-\mathrm{cc}^{\mathrm{a}}$ & \multicolumn{2}{|c|}{6} & 68 & \multicolumn{2}{|c|}{2} \\
\hline $5 \mathrm{Pu}^{\mathrm{b}}$ & \multicolumn{2}{|c|}{6} & 70 & \multicolumn{2}{|c|}{4} \\
\hline $6 \operatorname{Pr}^{\mathrm{b}}$ & \multicolumn{2}{|c|}{6} & 70 & \multicolumn{2}{|c|}{4} \\
\hline
\end{tabular}

\footnotetext{
${ }^{\text {a }}$ Between-subjects analysis

${ }^{\mathrm{b}}$ Within-subjects analysis

${ }^{c}$ From $1=$ not familiar at all to $5=$ very familiar

${ }^{\mathrm{d}}$ From $1=$ strongly disagree to $5=$ strongly agree
} 
Figure 1: The experimental structure of the Exchangeability Method

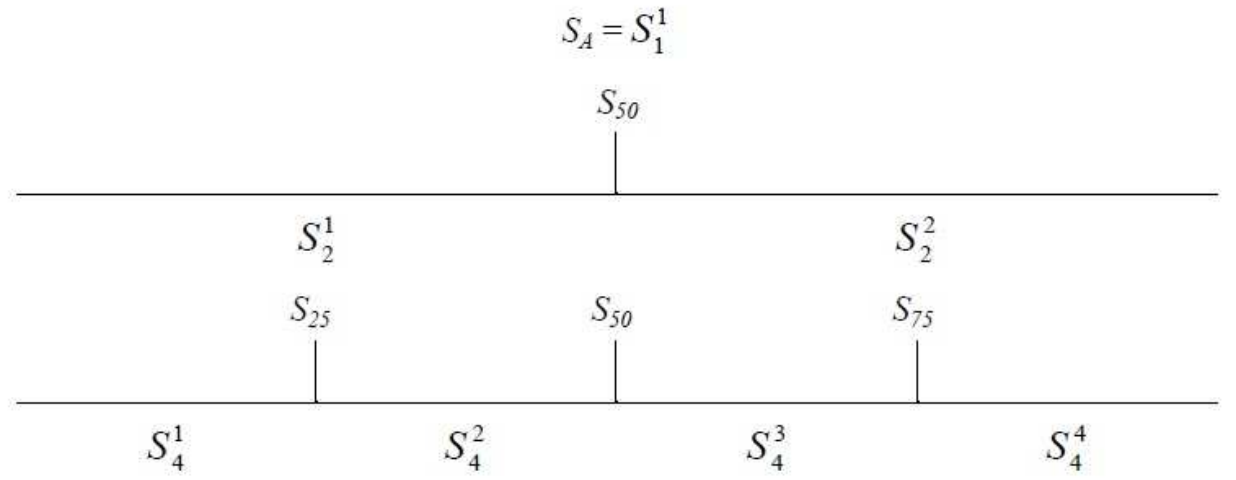

Figure 2: The first binary question of the Exchangeability Method (screenshot)

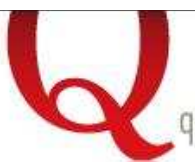

qualtrics.com

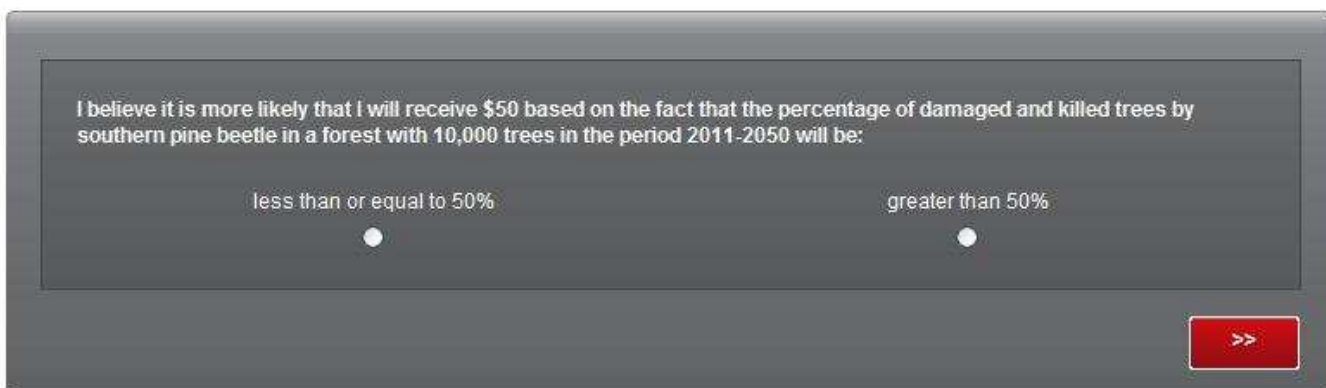

Survey Powered By Qusittics" 
Figure 3: Average subjective risk estimates of the pine beetle infestation rate

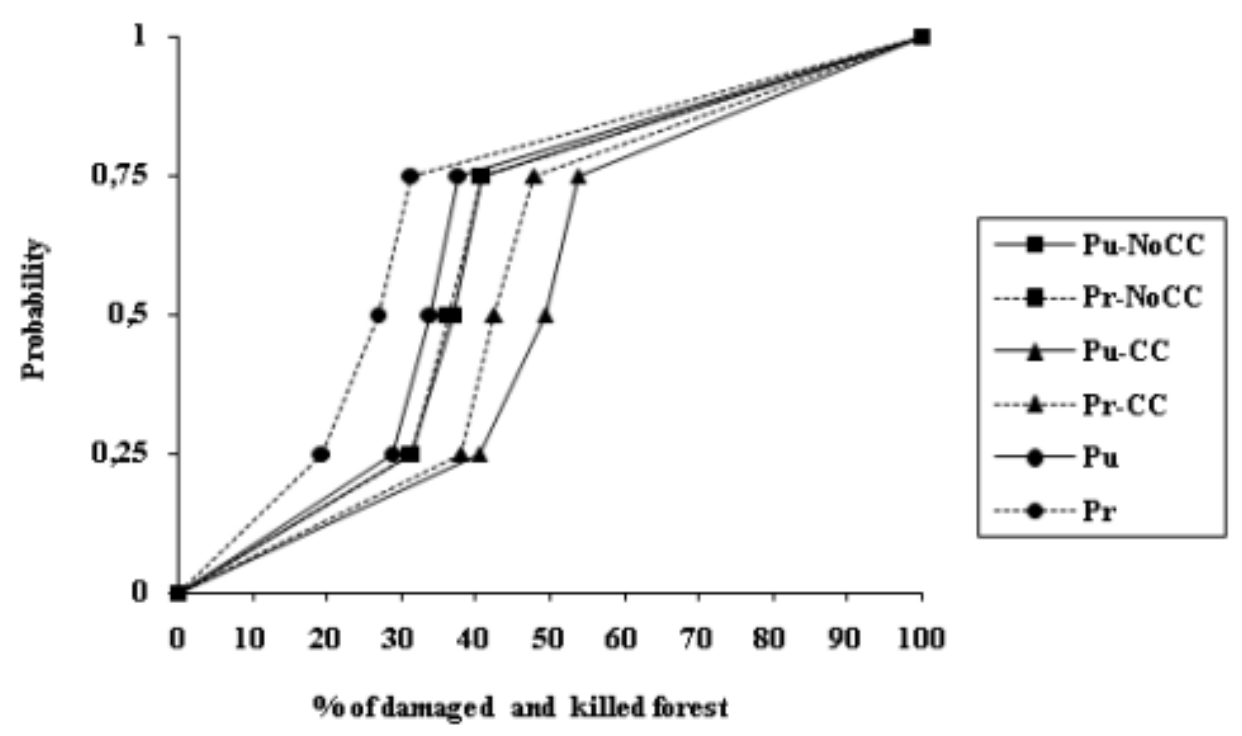

Figure 4a: Boxplot of variable $S_{25}$

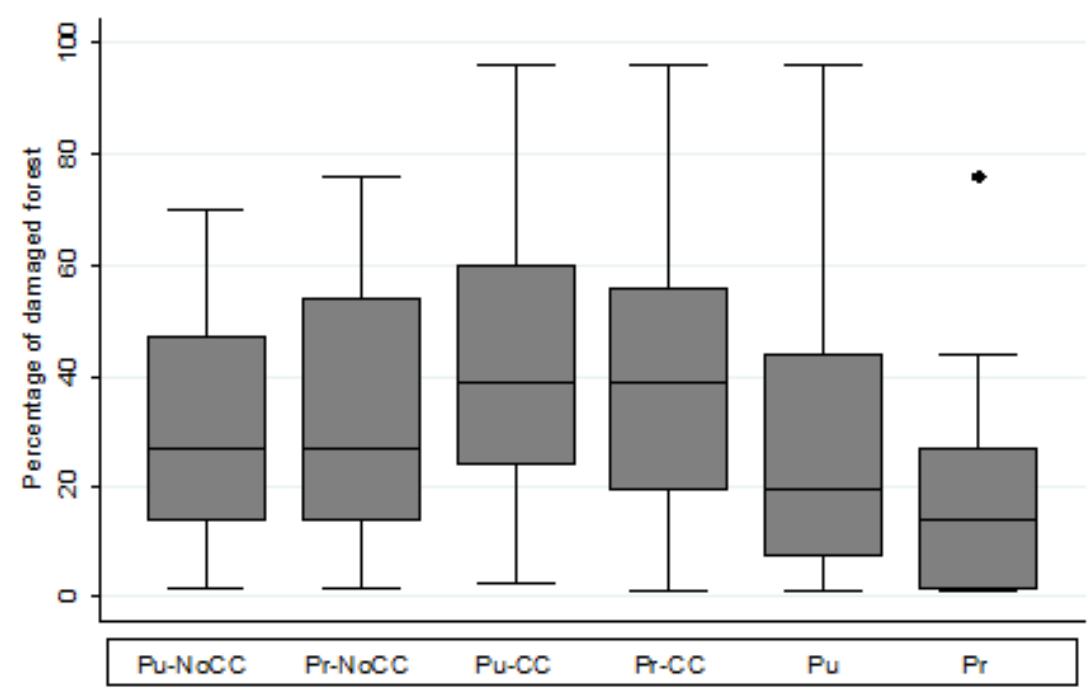


Figure 4b: Boxplot of variable $S_{50}$

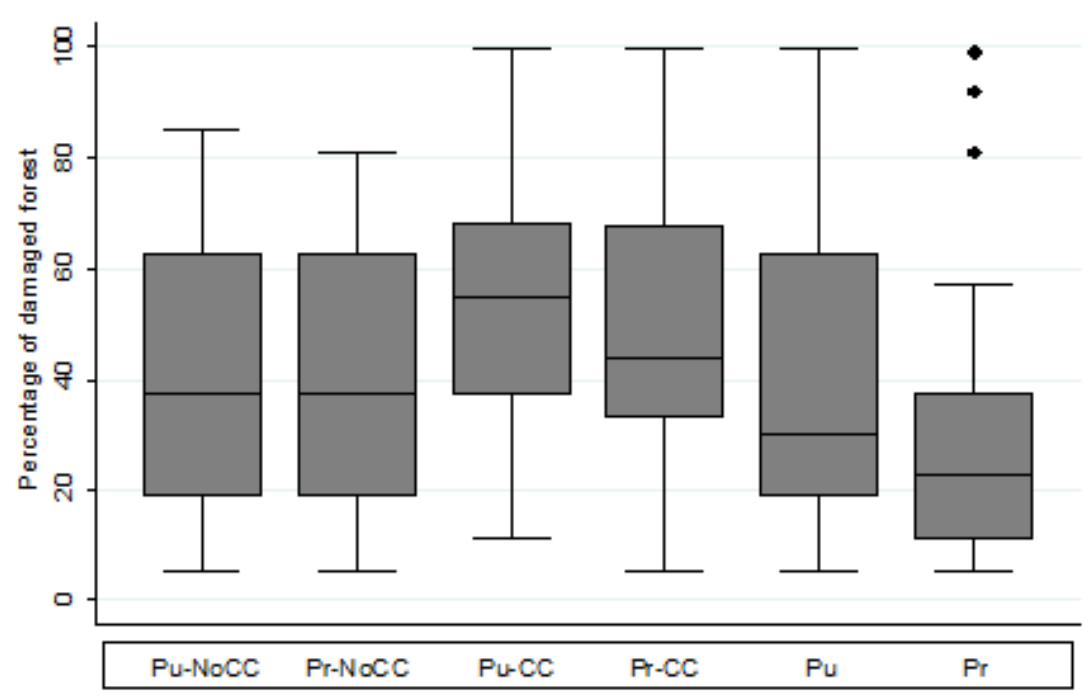

Figure 5c: Boxplot of variable $S_{75}$

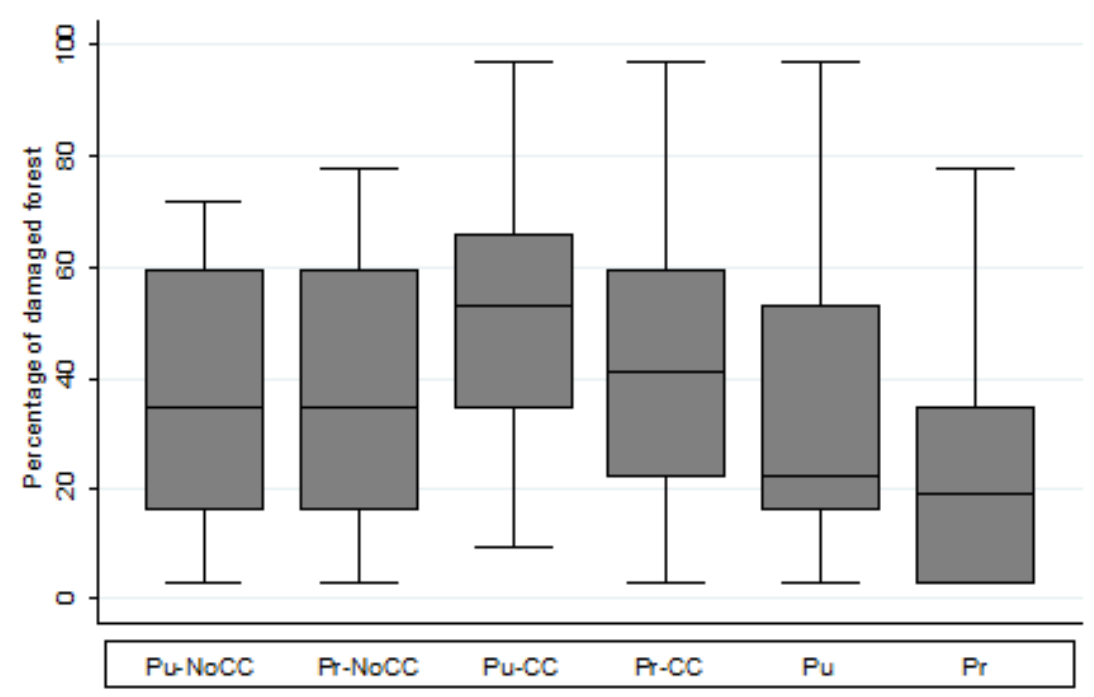




\section{Appendix A: Laboratory Instruction Text}

\section{Informed Consent Statement}

You are being asked to participate in an Economics Experiment that will explore how individuals make decisions when outcomes cannot be known with certainty. The experiment will last approximately 75 minutes. You will possibly earn money based upon the choices you make in this experiment. You may ask questions at any time during the experiment. If after the experiment is complete you have additional questions, please contact Dr. W. Douglass Shaw at wdshaw@tamu.edu or 979-845-3555. Your participation in this experiment is voluntary; your refusal to participate or discontinue participation will involve no penalty or loss of the benefits that you are entitled. By completing the questionnaire and experiment, you have expressed your willingness to participate.

Following the Informed consent, I will present each subject with the Subject's Bill of Rights.

EXPERIMENTAL SUBJECT'S BILL OF RIGHTS: The rights below are the rights of every person who is asked to be in a research study.

As an experimental subject, I have the following rights:

1. To be told what the study is trying to find out.

2. To be told what will happen to me and whether any of the procedures, drugs, or devices are different from what would be used in standard practice.

3. To be told about the frequent and / or important risks, side effects or discomforts of the things that will happen to me for research purposes.

4. To be told if I can expect any benefit from participating and, if so, what that benefit might be.

5. To be told what other choices I might have and how they may be better or worse than being in the study.

6. To be allowed to ask any questions concerning the study both before agreeing to be involved and during the course of the study.

7. To be told what sort of medical treatment is available if any complications arise.

8. To refuse to participate at all or to change my mind about participating after the study is started.

9. To receive a copy of the signed and dated consent form.

10. To be free of any pressure when considering whether I wish to agree to be in the study. 


\section{Section A: Getting Started}

I am Dr. X and helping me with the experiment today will be several assistants. All of us are in economics or agricultural economics.

Each of you is now seated at a computer terminal where you will enter responses to the questions. Please do not look at anyone else's responses, and do not discuss your responses with others.

You will be asked to complete several tasks, taking a maximum of about 75 minutes. As you know, you will receive a participation fee of $\$ 10$ as a way of showing our thanks for you being here, and giving up some time today.

\section{Your Chance of additional earnings}

Several of the questions also involve your making a choice that involves a potential payment. These choices involve a chance that an outcome will occur. At the end of the experiment we will randomly choose two subjects (there are about 25 subjects here today) from all of you is this section. We will do so by giving you an identification number that corresponds to your computer terminal number and letting one of you choose from a bag with numbered chips. If your number is drawn, you will be selected.

After that selection, we will randomly choose 4 tasks that the two selected subjects have answered (each of you has around 12 choices to answer). We will do so by giving to each task an identification number and letting one of you choose from a bag with numbered chips.

Finally, we will next flip a coin to determine the outcome for the questions that the two selected subjects have answered. If their choice corresponds to the "winning" outcome, the subject will be paid the amount corresponding to that question. If the choice corresponds to a "losing" outcome, based on the coin toss, then you earn nothing for that task.

You have the potential to earn between $\$ 0$ and $\$ 200$ based on the choices you make in addition to the participation fee of $\$ 10$ that you will receive. 
The choices that you make involve the potential risk of the Southern Pine Beetle pest in harming Texas pine forests. To begin, we would like to ask you about your thoughts about this pest (the Southern Pine Beetle) and the chance of pests invading and eliminating a percentage of a forest with 10,000 trees during the period 2010-2050. If you have no ideas or knowledge about these things, that is perfectly ok.

A1. On a scale from 1 to 5, how familiar are you with the Southern Pine Beetle? (mark the best number)
$\square 1$
$\square 2$
$\square 3$
$\square 4$
$\square 5$
I have heard of it
I know a bit
I am very familiar with it

Not at all familiar

A2. If you are willing to provide an estimate, what would you say the risk, or the chance is, of the Southern Pine Beetle eliminating $10 \%$ of the trees in a forest with 10,000 trees, like that red shaded area in the map below, during the period 2010-2050?

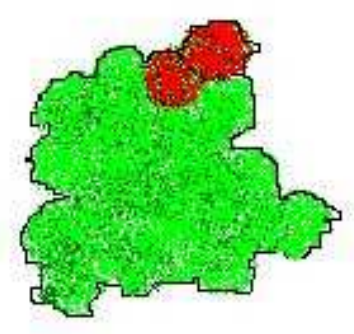

No Chance $0 \%$ $\%$

$100 \%$ It will definitely happen

A3. Answer below only if you are unable to answer A2. If you are not willing to provide an estimate, would you be willing to provide a range, say between the smallest chance it will happen, up to the highest chance it could happen?

No

Yes $\rightarrow \quad \ldots$ _ $\%$ (enter your range, for example, $5 \%$ to $50 \%$ ) 


\section{SECTION B Pests and Risks to Forests ${ }^{10}$}

The Southern Pine Beetle is an insect that thrives on pine trees, but unfortunately kills these trees by getting inside them. Texas has several stands of pine trees $(12,000,000$ acres), located on both private and public land. For example, see the map below.

The Southern Pine Beetle has already killed 1,2850,000 cords of pine pulpwood and about 1,540,000 Mbf (1,000 board feet) of pine saw-timber in Texas during the period 1960-2009. It is thought that the Southern Pine Beetle dies when very cold temperatures are reached, and that it thrives when warm and dry climatic conditions happen.

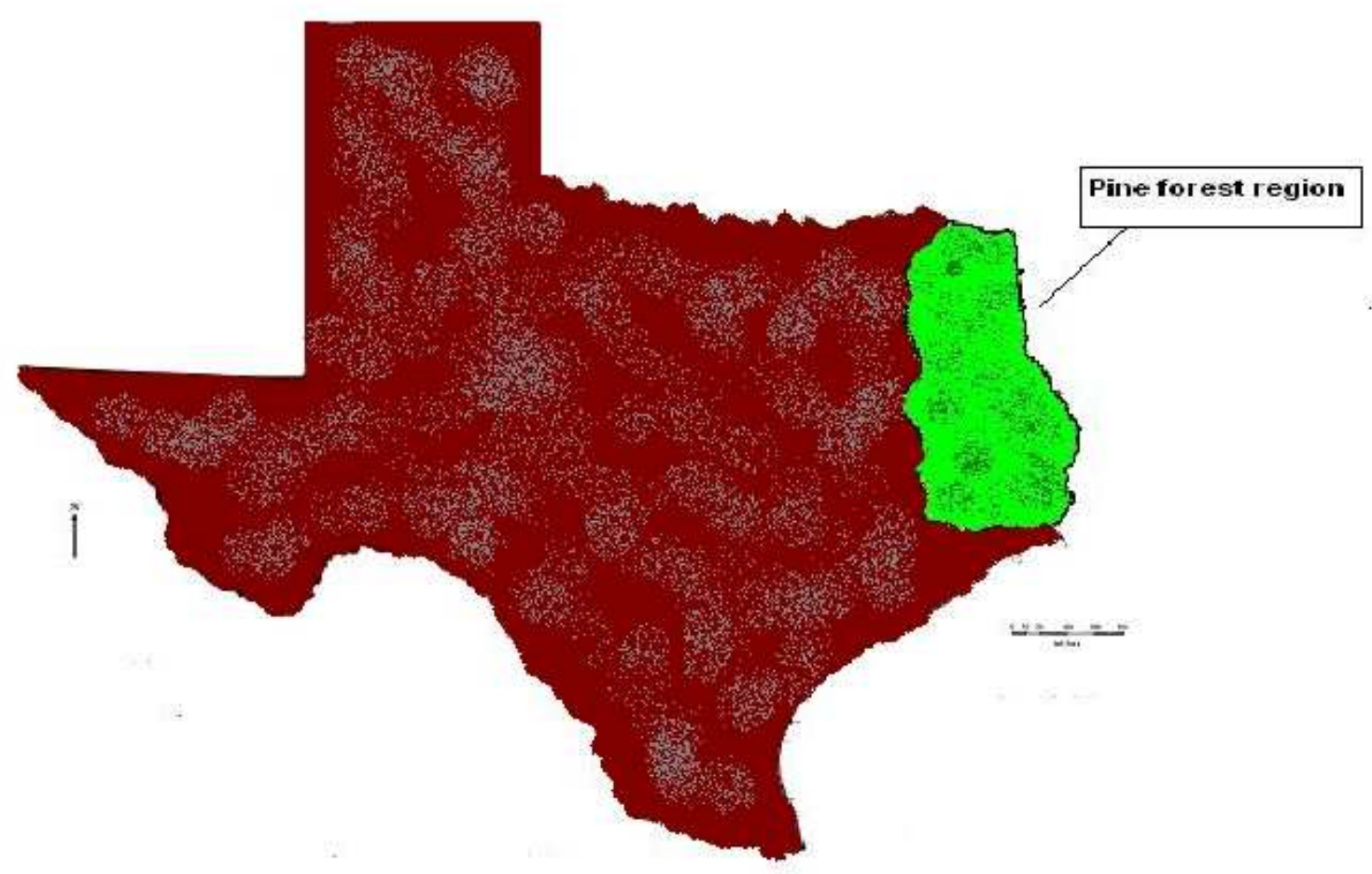

Now, consider a publically accessible pine forest with 10,000 trees. You can enjoy this forest any time you want for your recreational activities (hiking, jogging, doing picnic, etc.) without paying any entrance fee. This forest is not actually threatened by the southern pine beetle right now, but there is a chance that the southern pine beetle may damage and kill a percentage of trees of this forest in the future.

\footnotetext{
${ }^{10}$ This is the laboratory instruction text for the treatment "Public-climate change".
} 
The choices that you make involve the percentage of the trees of this public pine forest that you believe could be damaged and killed by the southern pine beetle in the period from 2010 to 2050 assuming that no pest control and no killed plant replacement will be implemented. In each question, you have to bet a certain amount of US \$ (as an example, \$50) choosing between two potential outcomes:

\section{EXAMPLE}

Outcome a. I believe the percentage of damaged and killed pine trees will be greater than or equal to $0 \%$ and less than or equal to $50 \%$ in a forest with 10,000 trees in the period 2011-2050.

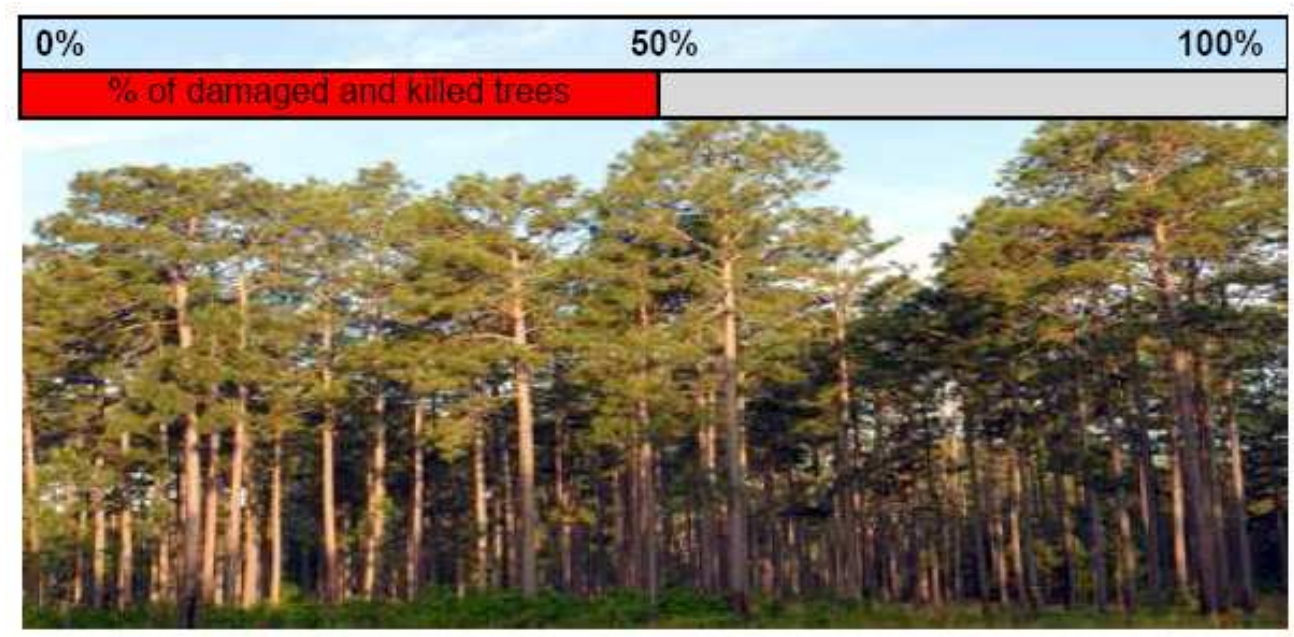

Outcome b. I believe the percentage of damaged and killed pine trees will be strictly greater than $50 \%$ and smaller than or equal to $100 \%$ in a forest with 10,000 trees in the period 2011-2050.

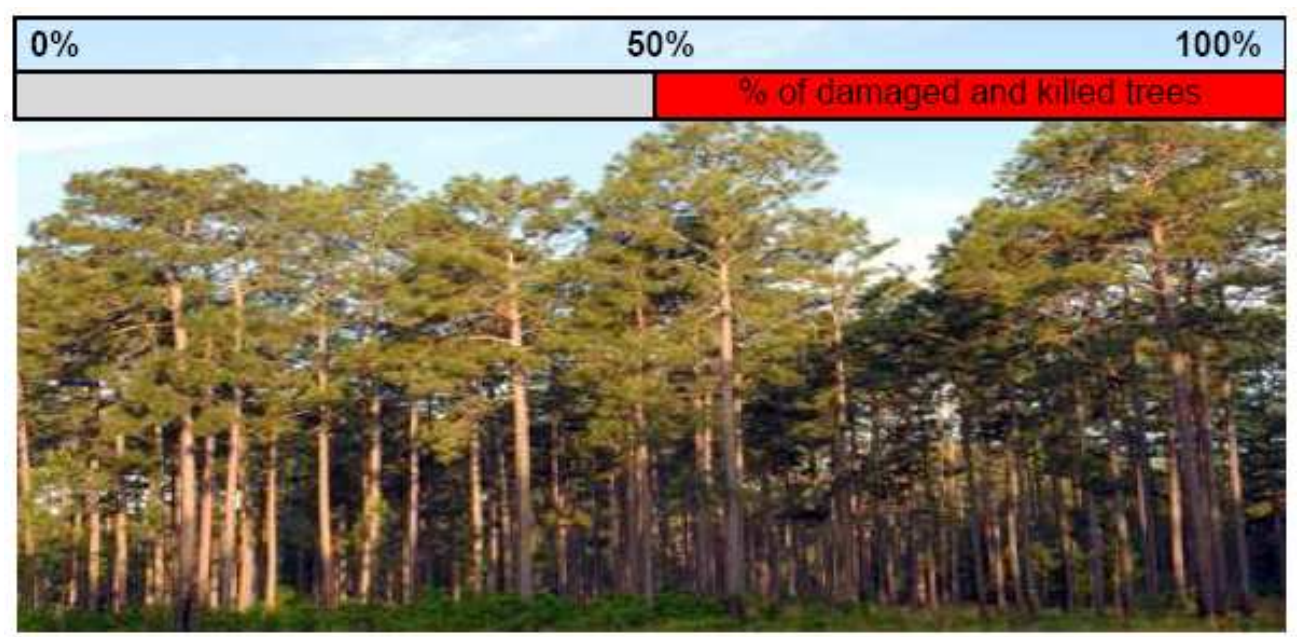


The occurrence of one of the two potential outcomes will be determined at the conclusion of the experiment by tossing a coin. Outcome a will be associated with a head, while Outcome b will be associated with tail.

If you choose to bet $\$ 50$ on the fact that the percentage value of damaged and killed pine trees will be greater than or equal to $0 \%$ and less than or equal to $50 \%$ in a forest with 10,000 trees in the period 2011-2050 (Outcome a) and if the outcome of coin toss is head you will earn $\$ 50$ if both the ID number of this particular question and your ID number will be selected, otherwise you will earn nothing.

Your goal will be to take home as much in extra earnings as you can. Your earnings will be determined by the choice you make in each task and by the outcome of coin toss.

For each question below, we would like you to express your opinion on the occurrence of two ranges of outcomes, each total range with the same likelihood of occurrence. You will be asked to state which of two outcome range contains the percentage of damaged trees you think is most likely to happen. If that event happens, after we play out the outcome, you might receive a certain monetary payment, for example, $\$ 50$, but if that event does not happen you receive nothing, but you will not lose any money either.

Ok, let's begin now with your tasks. Choose which you would prefer below.

EXCHANGEABILITY GAME (see Figure 2) 


\section{SECTION C: Debriefing and Questions About You}

C1. Do you or any relative or friend have past or current experience in the forest or timber industry?

No

Yes

C2. Have you ever visited a Texas forest for any purpose?

No

Yes (enter the name of it, if you can recall)

C3. Have you ever seat in a lecture, seminar or conference about climate change and pest on agriculture and forestry?

No

Yes

(enter the number of times, if you can recall)

C4. Have you ever watched a scientific TV program or read a scientific article about climate change and pest on agriculture and forestry?

No

Yes (enter the number of times, if you can recall)

C5. On a scale of 1 to 5, how familiar are you with the topic of global warming? (mark number)

\begin{tabular}{|c|c|c|c|c|}
\hline$\square 1$ & $\square 2$ & $\square 3$ & $\square 4$ & $\square 5$ \\
\hline $\begin{array}{c}\text { Not at all } \\
\text { familiar }\end{array}$ & \multicolumn{3}{|c|}{} & Very familiar \\
\hline
\end{tabular}


For the questions below, on a scale from 1 to 5 , please indicate your level of disagreement with the following statements (mark the best number to express your view):

C6. Scientists have demonstrated that global warming is already happening.

\begin{tabular}{|c|c|c|c|c|}
\hline$\square 1$ & $\square 2$ & $\square 3$ & $\square 4$ & $\square 5$ \\
\hline $\begin{array}{c}\text { Strongly } \\
\text { disagree }\end{array}$ & Disagree & $\begin{array}{c}\text { Neither } \\
\text { disagree or } \\
\text { agree }\end{array}$ & Agree & Strongly agree \\
\hline
\end{tabular}

C7. Scientists have demonstrated that global warming will definitely happen in the future.

\begin{tabular}{|c|c|c|c|c|}
\hline$\square 1$ & $\square 2$ & $\square 3$ & $\square 4$ & $\square 5$ \\
\hline $\begin{array}{c}\text { Strongly } \\
\text { disagree }\end{array}$ & Disagree & $\begin{array}{c}\text { Neither } \\
\text { disagree or } \\
\text { agree }\end{array}$ & Agree & Strongly agree \\
\hline
\end{tabular}

C8. Scientists have demonstrated that global warming is caused at least in part by humans emissions of carbon dioxide and other greenhouse gases.

\begin{tabular}{|c|c|c|c|c|}
\hline$\square 1$ & $\square 2$ & $\square 3$ & $\square 4$ & $\square 5$ \\
\hline $\begin{array}{c}\text { Strongly } \\
\text { disagree }\end{array}$ & Disagree & $\begin{array}{c}\text { Neither } \\
\text { disagree or } \\
\text { agree }\end{array}$ & Agree & Strongly agree \\
\hline
\end{tabular}

C9. At least some forests in the state of Texas should be open to the public so that all can enjoy forest-based recreation, such as hiking, camping, hunting, and swimming (if a lake is in the forest).

\begin{tabular}{|c|c|c|c|c|}
\hline$\square 1$ & $\square 2$ & $\square 3$ & $\square 4$ & $\square 5$ \\
\hline $\begin{array}{c}\text { Strongly } \\
\text { disagree }\end{array}$ & Disagree & $\begin{array}{c}\text { Neither } \\
\text { disagree or } \\
\text { agree }\end{array}$ & Agree & Strongly agree \\
\hline
\end{tabular}


Questions About YOU (We respect your privacy, and we will not match your responses with your name, nor make any attempt to identify you. Your responses can often explain why people answer certain questions in different ways)

C10. What is your current age?

C11. What is your gender? (mark) $\square \mathrm{M} \quad \square \mathrm{F}$

C12. How long have you lived in the state of Texas? years

C13. Do you come from a rural area or farm?

No $\quad$ Yes

C14. Have you, or do you ever do forest-based recreation in the outdoors?

No

Yes number of trips ____ years______ (enter the approximate number of recreational trips per year you took last year, or in the most recent year you took a trip

C15. Income often affects people's preferences for risk, so we need to ask this question. What is your approximate personal annual income including all sources? If you are a student, completely or partially dependent on parents for support, and know the category for your parent's household, please circle that category. (mark appropriate category)

$\square \quad$ Under $\$ 10,000$

$\square \quad \$ 10,000$ to $\$ 14,999$

口 $\$ 15,000$ to $\$ 19,999$

口 $\$ 20,000$ to $\$ 24,999$

口 $\$ 25,000$ to 29,999

$\quad \$ 30,000$ to 34,999

口 $\$ 35,000$ to 39,999

$\$ 40,000$ to 44,999

$\$ 45,000$ to 49,999

$\quad \$ 50,000$ to $\$ 54,999$

$\$ 55,000$ to $\$ 59,999$

$\$ 60,000$ to $\$ 69,999$

$\quad \$ 70,000$ to $\$ 79,999$

$\$ 80,000$ to $\$ 89,999$ 
$\$ 90,000$ to $\$ 99,999$

$\$ 100,000$ to $\$ 114,999$

- $\$ 115,000$ to $\$ 125,000$

Over $\$ 125,000$ 